\title{
A linear programming approach for structure optimization of Renewable-to-Chemicals (R2Chem) production networks
}

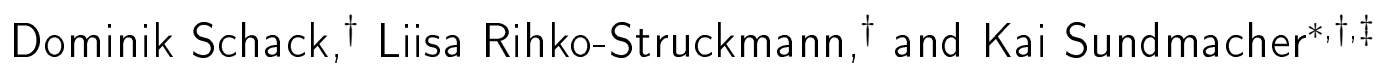 \\ †Max Planck Institute for Dynamics of Complex Technical Systems, Department Process \\ Systems Engineering, Sandtorstr.1, D-39106 Magdeburg, Germany \\ $\ddagger$ Otto-von-Guericke University Magdeburg, Department Process Systems Engineering, \\ Universitätsplatz 2, D-39106 Magdeburg, Germany \\ E-mail: sundmacher@mpi-magdeburg.mpg.de
}

\begin{abstract}
For $\mathrm{CO}_{2}$ reduction in the chemical industries, the massive use of renewable energies and the substitution of fossil based feedstock by implementation of Renewables-toChemicals (R2Chem) production systems are of key importance. Due to the multitude of alternative feedstock sources and process technologies a large number of different process pathways are possible for converting renewables into valuable target products. In this work we propose a method for the identification of the optimal R2Chem process structure under consideration of an economic objective function. By introducing process extent variables it is possible to fully avoid binary decision variables, resulting in a purely linear program. The derived cost function includes operational as well as capital cost. Furthermore, a penalty term for the carbon dioxide emission is considered. It is shown that an acceptable tradeoff between cost and emissions is realizable by using natural gas as feedstock source, especially if the required energy is supplied from


renewable sources. A net consumption of $\mathrm{CO}_{2}$ of the overall production system is only possible if renewable energies sources are exploited while using $\mathrm{CO}_{2}$ as feedstock source at the same time. In case of using fossil energy sources, a negative carbon footprint is unavoidable due to high indirect $\mathrm{CO}_{2}$-emissions due to the energy supply (electricity, heat). Thus, in addition to economic challenges of using $\mathrm{CO}_{2}$ as feedstock also the ecologic impact strongly depends on the energy source used. The main advantage of the proposed method is the fast screening for the optimal process system within a superstructure which contains many alternative process configurations. The method is exemplified by optimizing process systems for the production of methanol for different feedstock and energy supply sources.

\section{Introduction}

In recent years the importance for a more sustainable usage of available resources increased significantly in research and industry as well as in politics and society. A common agreement exists about the necessity of substituting fossil feedstock and energy carriers by renewable resources. However, an expansion of renewable power plants, e.g. wind farms or photovoltaic systems, and a simultaneous removal of base load plants leads unavoidably to major challenges caused by the high volatility of renewable energy sources (wind, solar). Due to fluctuating renewable energy supply to the grid, electrical surplus energy might become available which could be used for chemical processes. In this context, Power-to-X (PtX) processes could be a very attractive option for future chemicals production ${ }^{1-3}$. The principal step of PtX-concepts is the electrochemical splitting of water into hydrogen and oxygen via electrolysis and the subsequent utilization and/or storage of hydrogen ${ }^{4-6}$. Since in many areas, e.g. in the transportation sector, (synthetic) hydrocarbons will still be required in future, also sustainable carbon sources have to be identified. Different approaches for gaining or recycling of carbon exist. The most prominent way is the conversion of biomass by anaerobic digestion into (bio-)methane ${ }^{7-9}$ but also carbon capture and utilization (CCU) 
technologies are in the focus of research ${ }^{10-13}$. CCU seems to be very attractive since it offers the possibility to close the carbon cycle by recycling the bounded carbon atom in the carbon dioxide $\left(\mathrm{CO}_{2}\right)$ molecule.

From the perspective of sustainable chemical engineering, it is not only necessary to make use of electricity from renewables and to understand carbon dioxide as a raw material, but to substitute fossil resources by renewables, both in supplying energy and feedstock. We call this concept "Renewable-to-Chemicals" (R2Chem). It is obvious that a large number of different pathways exist for the production of one certain product. Therefore, the evaluation of all feasible pathways and the identification of the optimal one is essential. In this context it has to be specified what makes a pathway optimal. Many publications exist in the field of optimal pathway analysis. Otto et al. ${ }^{11}$ systematically listed chemical reactions that are able to convert carbon dioxide directly into valuable chemicals and evaluated these reactions by introducing different key-indicators, e.g. $\mathrm{CO}_{2}$-avoidance potential, market situation or independence of fossil reactants. Moreover, to identify optimal pathways superstructure approaches were often proposed that use economic objective functions ${ }^{14,15}$. Within these superstructure approaches different classes of optimization problems exist. A linear programming (LP) approach was used by Kim et al. ${ }^{16}$. They examined biomassto-fuel conversion strategies by means of decomposing the entire process into intermediate subprocesses and thereby identifying the most convenient mass flux distribution. Since in superstructure approaches very often binary decisions must be taken, many related mixed integer problem formulations can be found in literature ${ }^{17-19}$. As examples, three mixed integer linear programming (MILP) approaches are mentioned here. First, Maronese et al. ${ }^{20}$ examined biorefineries by detailed simulation of each conversion unit and subsequent mass flux optimization by interconnecting the units in a superstructure. Second, Ulonska et al. ${ }^{21}$ proposed an approach for evaluating biorefinery process pathways by applying reactor and separator shortcut models to estimate the overall energy demand. They optimized the mass fluxes and performed a pinch analysis subsequently to analyze the heat integration potential. 
Third, Kokossis et al. ${ }^{22}$ introduced a digraph approach for the optimization of the mass flux distribution. To account for the energetic demand they accomplished also a pinch analysis afterwards and designed a heat exchanger network.

However, for the optimization of the overall production process consisting of a variety of mass and energy fluxes it is not sufficient to optimize only the mass fluxes and to perform pinch analysis subsequently. For the identification of optimal process structures and exploiting synergy effects between single processes a simultaneous optimization of mass and energy fluxes is crucial. Therefore, the authors of this work presented in Schack et al. ${ }^{23}$ first ideas of a novel linear programming approach for the simultaneous optimization of mass and energy fluxes including heat integration. By introducing a continuous process extent variable it was possible to avoid binary decision variables. We applied a network theoretical approach and introduced nodes and edges to formulate a set of linear equations and inequalities in order to apply a linear programming program.

In the present work an improved and extended linear model formulation for the purpose of process network structure optimization is derived. In particular the improved heat integration model and the selection of an economic linear objective function are addressed here. Besides operational cost and capital cost for investment and internal heat transfer also penalty cost for $\mathrm{CO}_{2}$-emissions are considered. Hereby, we analyzed both the direct and indirect emissions that are caused by the energy supply. In order to illustrate our proposed methodology methanol is chosen as an important and valuable target molecule. Methanol is often mentioned in the Power-to-Chemicals context, since its synthesis reaction is well known $^{24,25}$ and numerous different modeling approaches exist in literature ${ }^{26,27}$. It can be synthesized either from a $\mathrm{CO}$ or $\mathrm{CO}_{2}$-rich syngas mixtures (Eqs. (1) and (2)). In order to adjust the optimal ratio between $\mathrm{CO}$ and $\mathrm{CO}_{2}$ also the reverse water gas shift reaction (RWGS) $)^{28,29}$ (Eq. (3)) has to be taken into account:

$$
\begin{gathered}
\mathrm{CO}+2 \mathrm{H}_{2} \longrightarrow \mathrm{CH}_{3} \mathrm{OH} \\
4 \\
\text { ACS Paragon Plus Environment }
\end{gathered}
$$




$$
\mathrm{CO}_{2}+3 \mathrm{H}_{2} \longrightarrow \mathrm{CH}_{3} \mathrm{OH}+\mathrm{H}_{2} \mathrm{O}
$$

$$
\mathrm{CO}_{2}+\mathrm{H}_{2} \longrightarrow \mathrm{CO}+\mathrm{H}_{2} \mathrm{O}
$$

One advantage of methanol is that it is a liquid at ambient conditions and therefore well suited to act as an energy storage molecule. Surplus electrical energy from renewables (wind, solar) can be used to produce hydrogen, which is converted in a subsequent process to gain methanol. The fluid can be stored and transported very easily. Furthermore, Otto et al. ${ }^{11}$ mentioned the large potential to use $\mathrm{CO}_{2}$ as feedstock for methanol production. In their evaluation of best products to recycle $\mathrm{CO}_{2}$ methanol is figured out as one of the most promising target molecules. Since the chemical activation of $\mathrm{CO}_{2}$ in order to use it as a chemical feedstock is one auspicious way to reduce the overall $\mathrm{CO}_{2}$-emission the usage of $\mathrm{CO}_{2}$-rich syngas gets increased interest for the production of methanol. For this reason, one can find microkinetic studies ${ }^{30}$ and thermodynamic exergy analysis ${ }^{31}$ evaluating the potential of methanol as target molecule.

To assess the ecological impact of chemical production networks, which can be improved by reducing the $\mathrm{CO}_{2}$-emission, not only the feedstock but also the energy source is crucial. It is insufficient to analyze only the direct $\mathrm{CO}_{2}$-emission, i.e. the $\mathrm{CO}_{2}$ that leaves the overall production process directly during the chemical conversion, but also the indirect emissions, e.g. $\mathrm{CO}_{2}$-emissions be attributed to the process energy demand. This is demonstrated in this study by analyzing both the economic impact, expressed as the specific production cost of methanol, and the ecological impact, expressed as specific $\mathrm{CO}_{2}$-emission. 


\section{Formulation of Process Network Model}

For representing the structure of a chemical production network we use a network theoretical approach by introduction of a directed graph. A directed graph consists of a set of nodes (or vertices) and a set of paired nodes (or directed edges). These edges connect each one pair of nodes and contain also the information about the edge direction. More detailed information can be found in adequate textbooks ${ }^{32}$.

In order to apply this concept for the structure optimization and identification of optimal pathways a node for each component that appears in the production network is introduced (Fig. 1). At these nodes a reference temperature $T_{0}$ and a reference pressure $p_{0}$ is considered. Between each pair of nodes the chemical conversion is considered, represented by a single process (Fig. 2), which is assumed to operate at average reaction temperature and pressure. All auxiliary operations, such as adjusting temperature and pressure, are presumed to happen inside these processes. In the next section, the governing equations and inequalities describing a process network are presented.

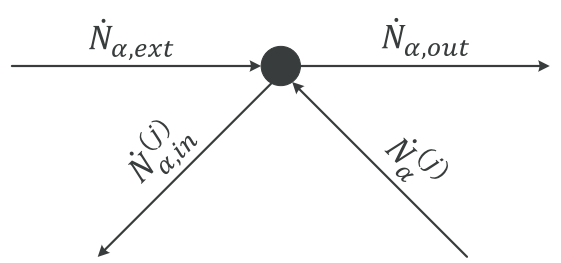

Figure 1: Components node

\section{Equality constraints}

\section{Modeling the mass fluxes}

As illustrated in Fig. 1 and 2 a node for each component $\alpha$ is introduced that has influents and effluents. Considering a chemical production plant besides the external mass fluxes that are fed into the system as initial reactants or are released to the outside as the final product, undesired by-products or waste, some mass fluxes appear only within the system envelope. 


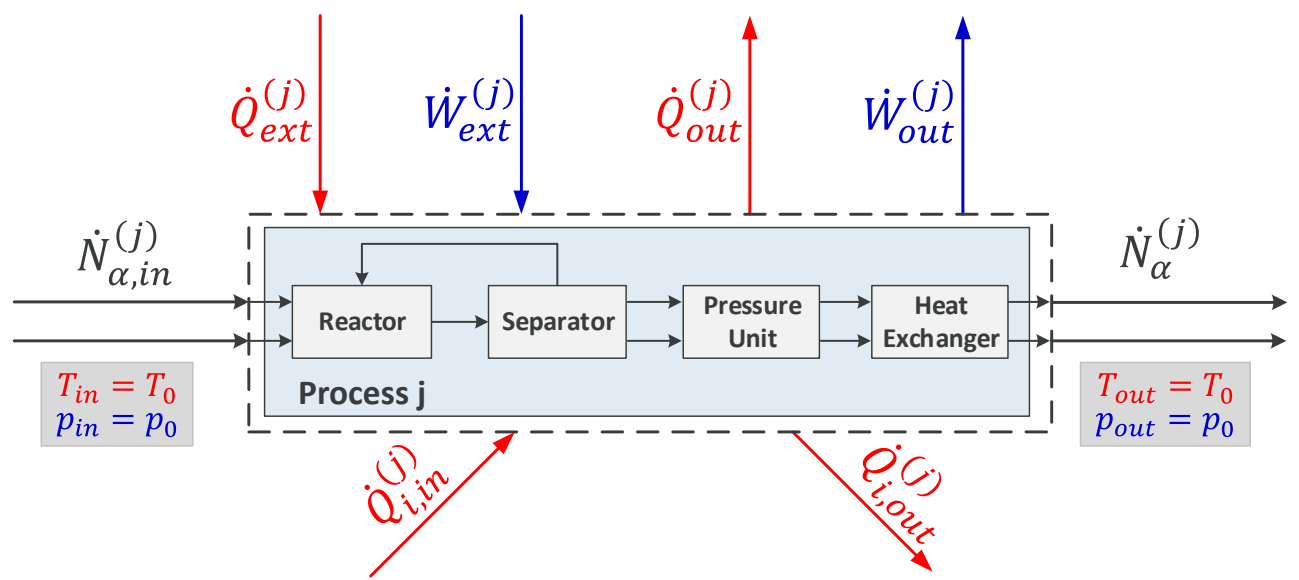

Figure 2: Mass conversion along the edges; schematic illustration of a single process consisting of reaction, separation and auxiliary operations such as heat and pressure adjustment

These internal mass fluxes correspond to the fluxes that enter or leave a single conversion process. In this way it is possible to account not only for the initial reactants and products but also for the intermediate components that are a product of one subprocess, only to be used as a reactant for another one. Balancing the internal and external mass fluxes at a component node as shown in Fig. 1 and assuming steady state we get:

$$
0=\dot{N}_{\alpha, \text { ext }}-\dot{N}_{\alpha, \text { out }}-\sum_{j=1}^{M} \dot{N}_{\alpha, \text { in }}^{(j)}+\sum_{j=1}^{M} \dot{N}_{\alpha}^{(j)} \quad \forall \alpha
$$

As shown in Fig. $1 \dot{N}_{\alpha, e x t}$ denotes the mass fluxes of component $\alpha$ that are fed into the production network and $\dot{N}_{\alpha, \text { out }}$ the fluxes that are released to the outside. The internal fluxes that enter the process $j$ or leave process $j$, respectively, illustrated in Fig. 2, are expressed by $\dot{N}_{\alpha, i n}^{(j)}$ and $\dot{N}_{\alpha}^{(j)}$.

The chemical conversion of a component $\alpha$ into another one is described by a stoichiometric model containing the stoichiometric coefficient of each component $\nu_{\alpha}$ and the process extent variable $\dot{\xi}$ :

$$
0=\dot{N}_{\alpha, i n}^{(j)}-\dot{N}_{\alpha}^{(j)}+\nu_{\alpha}^{(j)} \cdot \dot{\xi}^{(j)} \quad \forall \alpha, j
$$

The process extent variable $\dot{\xi}^{(j)}$ is adopted from the extent of reaction, which is widely 
used in chemical engineering to quantify the progress of a chemical reaction ${ }^{33}$. In contrast, here $\dot{\xi}^{(j)}$ quantifies how far the considered overall chemical production process $j$ proceeds (see Fig. 2). In this way both is possible, to describe the progress of a process and also if a process operates $\left(\dot{\xi}^{(j)} \neq 0\right)$ in the first place. By use of the process extent variable, it is not necessary to introduce any binary decision variable, i.e. the whole network model can be formulated solely in continuous variables.

Furthermore, pure and ideally separated in- and outlet mass fluxes are assumed. This assumption is done in order to avoid nonlinear effects, such as mixing effects, outside the system boundaries. It is important to mention that these effects are not neglected but only considered inside a single process which is treated as a black box.

\section{Modeling the energetic fluxes}

Besides mass fluxes it is important to account for the energetic fluxes that appear in a chemical production network. As shown in Fig. 2 each process $j$ interacts with heat fluxes $\dot{Q}$ and work fluxes $\dot{W}$. There are different reasons for the presence of energetic fluxes. First, depending on the endothermic or exothermic character of the chemical reactions taking place inside a process $j$, the main contribution to the net heat demand or surplus, respectively, is determined. However, heat fluxes are also caused due to separation tasks and/or adjusting a certain temperature level. The same applies for the work fluxes that are mainly caused by adjustment of the pressure as long as considering non-electrochemical processes. Regarding electrochemical processes electrical energy is not only required for separation or compression but it is supplied to proceed electrolytic reactions. Again, depending on the considered process the electrical energy is required or released during the conversion process. Since the overall process is balanced as shown in Fig. 2, the single contributions of the unit operations (reaction, separation, heat and pressure adjustment) to the energy demand or surplus is not expressed individually but only considered as part of the net heat and net work.

In analogy to mass fluxes one has to distinguish between internal and external heat 
fluxes. External fluxes correspond to fluxes that are transferred between a process $j$ and external heating/cooling utilities. To minimize the external net heat supply and to increase the overall process efficiency the possibility for internal heat transfer must be included in this analysis. Therefore, the internal heat fluxes correspond to heat fluxes that are transferred between processes $j$ and $i$. The most established approach for the process heat integration is pinch analysis ${ }^{34}$ where the hot and cold utility usage is minimized. Furthermore, information about temperature levels, at which the heat is transferred, is obtained. Heat integration using pinch analysis is mostly performed after mass-based chemical process design. Instead, here we are aiming at an integrated design concept that is presented in the following. First, an enthalpy balance for each process $j$ is formulated (Eq. (6)) to identify the net energy demand or surplus according to the first law of thermodynamics for steady-state flow conditions:

$$
\begin{aligned}
0= & \sum_{\alpha=1}^{N} h_{\alpha, i n} \dot{N}_{\alpha, \text { in }}^{(j)}-\sum_{\alpha=1}^{N} h_{\alpha} \dot{N}_{\alpha}^{(j)}+\dot{Q}_{\text {ext }}^{(j)}-\dot{Q}_{\text {out }}^{(j)} \\
& +\sum_{i=1}^{M}\left(\dot{Q}_{i, \text { in }}^{(j)}-\dot{Q}_{i, \text { out }}^{(j)}\right)+\dot{W}_{\text {ext }}^{(j)}-\dot{W}_{\text {out }}^{(j)} \quad \forall j
\end{aligned}
$$

As shown in Fig. 2 the temperature level of inlet and outlet streams is assumed to be equal. The enthalpy difference term in Eq. (6) can be expressed by means of the enthalpy of reaction $\Delta_{R} h^{(j)}$ :

$$
\sum_{\alpha=1}^{N} h_{\alpha, i n} \dot{N}_{\alpha, i n}^{(j)}-\sum_{\alpha=1}^{N} h_{\alpha} \dot{N}_{\alpha}^{(j)}=-\Delta_{R} h^{(j)} \cdot \dot{\xi}^{(j)} \quad \forall j
$$

In Eq. (6) $\dot{Q}_{e x t}^{(j)}$ denotes the heat fluxes that are supplied from external heat utilities to the process $j$ and $\dot{Q}_{\text {out }}^{(j)}$ the heat fluxes that are released to the outside from process $j$, respectively. The same applies to the external work fluxes $\dot{W}_{e x t}^{(j)}$ and $\dot{W}_{\text {out }}^{(j)}$. The heat fluxes $\dot{Q}_{i, \text { in }}^{(j)}$ and $\dot{Q}_{i, \text { out }}^{(j)}$ are the heat fluxes that are transferred between processes $j$ and $i$ in the direction shown in Fig. 2. When neglecting any heat transfer losses, the heat flux that is 
transferred from process $j$ into process $i$ is equal to the heat flux that process $i$ receives from $j$. This fact is expressed by the following equation:

$$
0=\dot{Q}_{i, \text { in }}^{(j)}-\dot{Q}_{j, \text { out }}^{(i)} \quad \forall i, j
$$

\section{Modeling the entropy production}

The second law of thermodynamics has to be considered in order to account not only for the net heat and work fluxes but also for the ratio of the two energetic fluxes. Therefore, besides an enthalpy balance an entropy balance is formulated. The entropy production due to irreversible processes is estimated by introducing an energy conversion efficiency $\eta^{(j)}$ for each process $j$. Then, assuming steady-state the entropy balance can be written as follows:

$$
\begin{aligned}
0= & \sum_{\alpha=1}^{N} s_{\alpha, \text { in }} \dot{N}_{\alpha, \text { in }}^{(j)}-\sum_{\alpha=1}^{N} s_{\alpha} \dot{N}_{\alpha}^{(j)}-\frac{1}{T_{j}}\left(\dot{Q}_{\text {ext }}^{(j)}-\dot{Q}_{\text {out }}^{(j)}+\sum_{i=1}^{M} \dot{Q}_{i, \text { in }}^{(j)}-\sum_{i=1}^{M} \dot{Q}_{i, \text { out }}^{(j)}\right) \\
& -\frac{1}{T_{j}}\left(\left(1-\eta^{(j)}\right) \dot{W}_{\text {ext }}^{(j)}+\left(\frac{1}{\eta^{(j)}}-1\right) \dot{W}_{\text {out }}^{(j)}\right) \quad \forall j
\end{aligned}
$$

Again, if equal temperatures of inlet and outlet streams (Fig. 2) are assumed, the entropy difference can be expressed by means of reaction entropy $\Delta_{R} s^{(j)}$.

$$
\sum_{\alpha=1}^{N} s_{\alpha, i n} \dot{N}_{\alpha, i n}^{(j)}-\sum_{\alpha=1}^{N} s_{\alpha} \dot{N}_{\alpha}^{(j)}=-\Delta_{R} s^{(j)} \cdot \xi^{(j)} \quad \forall j
$$

While the entropy contribution of work in fully reversible processes $\left(\eta^{(j)}=1\right)$ becomes zero, any irreversibilities contribute to the last term of Eq. (9). The influence of the energy conversion efficiency on the net energy fluxes is illustrated in Fig. S1 for the example of PEM water electrolysis. It becomes obvious, that for a reversible process $\left(\eta^{(j)}=1\right)$ PEM water electrolysis appears as a heat sink (positive net heat flux) while it becomes a heat source (negative net heat flux) if its efficiency is decreased. 


\section{Inequality constraints}

\section{Modeling the internal heat transfer}

When modeling the internal heat transfer, besides the availability of heat it is important to ensure that heat can be only transferred from higher to lower temperature levels. This can be achieved by formulating two linear inequalities. First, the maximal internal heat flux from process $i$ into process $j$ depending on the temperature levels and minimum temperature difference $\Delta T_{\min }$ is determined. $\Delta T_{\min }$ is adopted from pinch analysis ${ }^{34}$ and ensures a minimum driving force for the heat transfer.

$$
0 \leq \frac{T_{i}-T_{0}-\Delta T_{\min }}{T_{j}-T_{0}}\left(\dot{Q}_{e x t}^{(j)}+\sum_{k=1}^{M} \dot{Q}_{k, i n}^{(j)}\right)-\dot{Q}_{i, i n}^{(j)} \quad \forall i, j
$$

Eq. (11) ensures that only as much heat is transferred into process $j$ as the temperature level of heat supplying process $i$ allows. In order to guarantee this heat transfer constraint not only for a single process but for the overall production system a second inequality for each pair of heat supplying processes $i$ and $l$ interacting with one heat receiving process $j$ has to be fulfilled:

$$
0 \leq \frac{T_{i, l}^{\max }-T_{0}-\Delta T_{\min }}{T_{j}-T_{0}}\left(\dot{Q}_{e x t}^{(j)}+\sum_{k=1}^{M} \dot{Q}_{k, i n}^{(j)}\right)-\dot{Q}_{i, i n}^{(j)}-\dot{Q}_{l, i n}^{(j)} \quad \forall i, j, l
$$

The resulting mean temperature difference between heat supplying process $i$ and heat receiving process $j$, and hence the driving force of the heat transfer, is shown in Fig. S2. This temperature difference depends on the supply temperature of the initial reactants that are fed into the system, which is assumed to be the reference temperature $T_{0}$ at the chemical component nodes.

Due to information loss caused by balancing heat and work fluxes by means of only one overall enthalpy balance (see Eq. (6)) two further inequalities (Eq. (13)) are introduced. These conditions ensure for all non-electrochemical processes $k$ that the enthalpy change due to a certain chemical reaction corresponding to the enthalpy of reaction is only supplied 
or released in the form of heat.

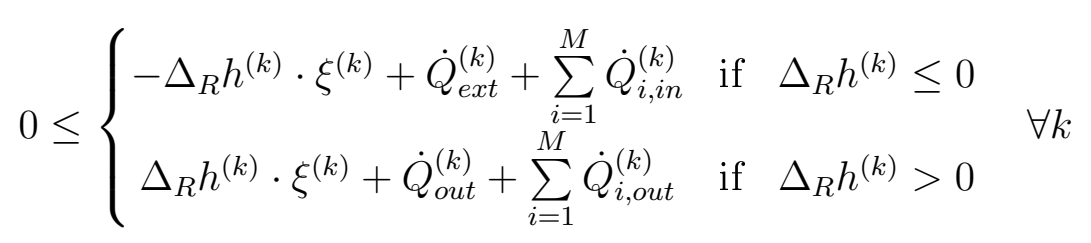

\section{Optimization problem and objective function formulation}

For the identification of the optimal process network for converting renewables into chemicals (R2Chem), the following linear programming problem is formulated:

$$
\begin{aligned}
& \min _{\mathbf{x}} f(\mathbf{x})=\mathbf{c}^{\top} \mathbf{x} \\
& \text { s.t. } \mathbf{A}_{\mathrm{eq}} \mathbf{x}=\mathrm{b}_{\mathrm{eq}} \\
& \mathrm{Ax} \leq \mathrm{b} \\
& \mathrm{lb} \leq \mathrm{x} \leq \mathrm{ub}
\end{aligned}
$$

In Eq. (14), $f$ is the objective function and $\mathbf{x}=(\dot{\mathbf{N}}, \dot{\boldsymbol{\xi}}, \dot{\mathbf{Q}}, \dot{\mathbf{W}})^{\top}$ the vector of decision variables containing all the fluxes appearing in the overall process network system. The coefficient matrices $\mathbf{A}_{\mathbf{e q}}, \mathbf{A}$ and right-hand-side vectors $\mathbf{b}_{\mathbf{e q}}$, $\mathbf{b}$ of the linear systems are determined from the equalities and inequalities, respectively, given in prior sections.

The lower lb and upper bounds ub have either physical reasons or are specified by the considered processes and operation conditions, see Tab. 1.

Table 1: Lower and upper bounds

\begin{tabular}{l|cc}
\hline Description & Lower Bound & Upper Bound \\
\hline Non-negativity conditions & $\mathbf{0} \leq(\dot{\mathbf{N}}, \dot{\boldsymbol{\xi}}, \dot{\mathbf{Q}}, \dot{\mathbf{W}})^{\top}$ & \\
Minimum input mass fluxes & $\dot{\mathbf{N}}_{\text {ext }}^{\text {min }} \leq \dot{\mathbf{N}}_{\text {ext }}$ & \\
Minimum output mass fluxes & $\dot{\mathbf{N}}_{\text {out }}^{\text {min }} \leq \dot{\mathbf{N}}_{\text {out }}$ & \\
Maximum input mass fluxes & & $\dot{\mathbf{N}}_{\text {ext }} \leq \dot{\mathbf{N}}_{\text {ext }}^{\max }$ \\
Maximum output mass fluxes & & $\dot{\mathbf{N}}_{\text {out }} \leq \dot{\mathbf{N}}_{\text {out }}^{\text {max }}$ \\
Non-electrochemical process & & $\dot{\mathbf{W}}_{\text {out }}=\mathbf{0}$ \\
El.chemical process $\left(\Delta_{R} h>0\right)$ & & $\dot{\mathbf{W}}_{\text {out }}=\mathbf{0}$ \\
\hline
\end{tabular}

It is reasonable to evaluate the different pathways by means of economic quantities. In 


$$
\mathrm{TAC}=C_{P}+C_{H, s}+C_{H, r}+C_{E, s}+C_{C O_{2}}+\frac{\left(C_{H X}+C_{I}\right) z}{1-(z+1)^{-n}}
$$

TAC can be divided into operational and capital cost. In contrast to operational cost that are caused by the operation of the production process, the capital cost have to be paid for the plant investment. In the following sections the single terms of the objective function are derived. In particular our linear model approach for describing the capital cost, which can be divided into general investment cost and cost for internal heat transfer, is presented.

\section{Modeling the operational cost}

The operational cost vary and depend on the process conditions. Besides cost for the reactants which are directly linked to the feedstock consumption, the energy consumption causes expenditures as well. In Schack et al. ${ }^{23}$ we introduced cost factors in order to weight the different cost contributions. These cost factors are given in Tab. 2 .

Table 2: Modeling the operational cost

\begin{tabular}{ll}
\hline Cost contribution & Equation \\
\hline Purchase of reactants & $C_{P}=\sum_{\alpha=1}^{N} c_{\alpha}^{P} \cdot \dot{N}_{\alpha, e x t}$ \\
Supplying of heat & $C_{H, s}=\sum_{j=1}^{M} c^{H, s} \cdot \dot{Q}_{e x t}^{(j)}$ \\
Removing of heat & $C_{H, r}=\sum_{j=1}^{M} c^{H, r} \cdot \dot{Q}_{o u t}^{(j)}$ \\
Supplying of work & $C_{E, s}=\sum_{j=1}^{M} c^{E, s} \cdot \dot{W}_{e x t}^{(j)}$ \\
\hline
\end{tabular}




\section{Modeling the investment cost}

The investment $\operatorname{cost} C_{I}$ typically depends on the size of the production capacity. Several correlations are available for the cost estimation in literature ${ }^{35-37}$. A correlation defined by Lange ${ }^{38}$ between energy losses of a chemical production plant and its corresponding investment cost is applied in our approach ${ }^{39}$. This correlation is given in Eq. (16).

$$
C_{I}^{\text {Lange }}=a\left(E_{\text {loss }}\right)^{b}
$$

According to Lange ${ }^{38} a$ and $b$ are regression parameters $(a=3.0, b=0.84), E_{\text {loss }}[\mathrm{MW}]$ the energy loss and $C_{I}\left[10^{6}\right.$ USD] the investment cost. The energy loss (Eq. (18)) is defined as difference of the lower heating values of the reactants including fuel and lower heating values of the products. This correlation gives a quite reliable estimation of the investment cost, especially if the process is far from heat-neutral having only minor energy losses ${ }^{38}$. Lange also addressed a nearly linear dependency of the investment cost on the energy loss as illustrated in Fig. S3. Therefore, the investment cost in our model is linearized according to Eq. (17).

$$
c_{I}^{(j)}=p_{1} E_{\text {loss }}^{(j)}+p_{2} \quad \forall j
$$

The energy loss $E_{\text {loss }}^{(j)}$ of each process $j$ is calculated as follows:

$$
E_{\text {loss }}^{(j)}=\sum_{\alpha=1}^{N}\left(\Delta h_{u, \alpha}^{(j)} \dot{N}_{\alpha, i n}^{(j)}+\Delta h_{u, f u e l}^{(j)} \dot{N}_{\text {fuel }}^{(j)}-\Delta h_{u, \alpha}^{(j)} \dot{N}_{\alpha}^{(j)}\right) \quad \forall j
$$

The molar flux of the fuel is directly linked to the required heat and work demand. Due to heat transfer losses and also losses caused by energy conversion efficiency factors $\eta_{h t}$ and $\eta_{e c}$ are introduced, respectively.

$$
\begin{gathered}
\dot{N}_{\text {fuel }}^{(j)}=\frac{\dot{Q}_{\text {fuel }}^{(j)}}{\Delta h_{u, f u e l}^{(j)}} \quad \forall j \\
\text { ACS Paragon Plus Environment }
\end{gathered}
$$




$$
\dot{Q}_{\text {fuel }}^{(j)}=\frac{1}{\eta_{h t}}\left(\dot{Q}_{\text {ext }}^{(j)}+\sum_{i=1}^{M} \dot{Q}_{i, i n}^{(j)}\right)+\frac{1}{\eta_{e c}} \dot{W}_{\text {ext }}^{(j)} \quad \forall j
$$

Finally, the overall investment $\operatorname{cost} C_{I}$ of the entire production network system is then estimated by addition of the contributions of each process $j$ :

$$
\begin{aligned}
C_{I}= & \sum_{j=1}^{M} p_{1} \sum_{\alpha=1}^{N}\left(\Delta h_{u, \alpha}^{(j)} \dot{N}_{\alpha, i n}^{(j)}-\Delta h_{u, \alpha}^{(j)} \dot{N}_{\alpha}^{(j)}\right) \\
& +\sum_{j=1}^{M} p_{1}\left(\frac{1}{\eta_{h t}}\left(\dot{Q}_{e x t}^{(j)}+\sum_{i=1}^{M} \dot{Q}_{i, i n}^{(j)}\right)+\frac{1}{\eta_{e c}} \dot{W}_{e x t}^{(j)}\right)+p_{2}
\end{aligned}
$$

\section{Modeling the heat exchanger cost}

The heat exchanger cost are assumed to be linearly dependent on the size of the heat exchanger.

$$
C_{H X}=c_{H X} \cdot A_{H X}
$$

Herein $C_{H X}$ denotes the total cost of the heat exchanger and $c_{H X}$ the area specific cost in $€ / \mathrm{m}^{2}$. The heat exchanger area $A_{H X}$ can be calculated from the transferred heat flux $\dot{Q}$ and heat transfer coefficient $k$ :

$$
A_{H X}=\frac{\dot{Q}}{k \cdot \Delta T_{m}}
$$

The logarithmic mean temperature difference $\Delta T_{m}$ depends on the temperature differences at both ends of the heat exchanger $\Delta T_{1}$ and $\Delta T_{2}$. For the calculation of the temperature differences the heating from (for heat receiving processes) or the cooling to the reference level (for heat supplying processes) is considered.

$$
\Delta T_{m}=\frac{\Delta T_{1}-\Delta T_{2}}{\ln \Delta T_{1}-\ln \Delta T_{2}}
$$


Using Eqs. (22) and (23) the cost for the heat exchangers required to transfer the internal heat fluxes for each process $j$ is given:

$$
C_{H X}^{(j)}=\sum_{i=1}^{M} c_{i}^{(j)} \cdot \dot{Q}_{i, i n}^{(j)} \quad \forall j
$$

Herein the cost factor $c_{i}^{(j)}$ is defined as:

$$
c_{i}^{(j)}=\frac{c_{H X}}{k \cdot \Delta T_{i, m}^{(j)}} \quad \forall j
$$

Finally, the total heat exchanger cost are calculated by summation of all heat exchangers required to transfer heat between processes $j$ and $i$ :

$$
C_{H X}=\sum_{j=1}^{M} \sum_{i=1}^{M}\left(\frac{c_{H X}\left(\ln \Delta T_{i, 1}^{(j)}-\ln \Delta T_{i, 2}^{(j)}\right)}{k\left(\Delta T_{i, 1}^{(j)}-\Delta T_{i, 2}^{(j)}\right)} \cdot \dot{Q}_{i, i n}^{(j)}\right)
$$

\section{Modeling the penalty for $\mathrm{CO}_{2}$ emissions}

Besides capital and operational cost introduced above, also cost caused by $\mathrm{CO}_{2}$ emissions have to be integrated into the cost estimation. They can be attributed to $\mathrm{CO}_{2}$-certificate cost for emitting carbon dioxide. The intention is to limit emissions by means of mandatory purchase of the $\mathrm{CO}_{2}$-certificates whose price is subject to political decision. The emission itself constitutes on the one hand directly by the stoichiometrically co-produced carbon dioxide from the production network $\dot{N}_{\mathrm{CO}_{2} \text {,out }}$ and on the other hand indirectly by energy consumption which is influenced by the process chemistry and also by the process energetic efficiencies. The lower the efficiency the more energy is required. If the energy demand cannot be supplied internally the external source causes the energy specific carbon dioxide emission $e_{\mathrm{CO}_{2}}$. Hence, a combination of political penalty, identification of a suitable and sustainable source and finally improving the technology influences the cost caused by $\mathrm{CO}_{2}$ emission. 


$$
C_{\mathrm{CO}_{2}}=c_{\mathrm{CO}_{2}}\left(e_{\mathrm{CO}_{2}, \dot{Q}} \cdot \sum_{j=1}^{M} \dot{Q}_{\text {ext }}^{(j)}+e_{\mathrm{CO}_{2}, \dot{W}} \cdot \sum_{j=1}^{M} \dot{W}_{\text {ext }}^{(j)}+\dot{N}_{\mathrm{CO}_{2}, \text { out }}\right)
$$

\section{Case Study: Methanol Production}

\section{Thermodynamic fundamentals}

In order to apply the methodology derived in the previous section some thermodynamic quantities are required. Considering Eqs. (6) and (9) one can see that enthalpies and entropies of pure components are used to calculate the energetic heat and work fluxes. Assuming ideal gas behavior the enthalpy $h$ of a pure component is pressure independent but a function of temperature and can be calculated if a reference enthalpy, e.g. the enthalpy of formation $\Delta h_{f}$ at standard temperature $T_{0}=298.15 \mathrm{~K}$ is known.

$$
h_{\alpha}(T)=\Delta h_{f}\left(T_{0}\right)+\int_{T_{0}}^{T} c_{p, \alpha}(T) \mathrm{d} T
$$

For the calculation of the entropy $s$ temperature and pressure dependence have to be considered. Again, the temperature difference of a known entropy, e.g. the entropy of formation $\Delta s_{f}$ at standard temperature, is expressible by means of the heat capacity $c_{p}$.

$$
s_{\alpha}(T, p)=\Delta s_{f}\left(T_{0}\right)+\int_{T_{0}}^{T} \frac{c_{p, \alpha}(T)}{T} \mathrm{~d} T-R \int_{p_{0}}^{p} \frac{\mathrm{d} p}{p}
$$

Since the heat capacities in Eqs. (29) and (30) are temperature dependent a functional relation between heat capacity and temperature is required. In literature many polynomial fitting approaches of experimental derived values are published ${ }^{40}$. We applied the Shomate equation (Eq.(31)) with listed parameters from NIST ${ }^{41}$.

$$
c_{p}(T)=A+B\left(\frac{T}{1000}\right)+C\left(\frac{T}{1000}\right)^{2}+D\left(\frac{T}{1000}\right)^{3}+E\left(\frac{T}{1000}\right)^{-2}
$$


The parameters $A, B, C, D$ and $E$ as well as $\Delta h_{f}$ and $\Delta s_{f}$ are given in Tab. S1 for the species appearing in this study. Furthermore, the lower heating values $\Delta h_{u}$, required for the calculation of energy loss in order to estimate the investment cost are listed.

\section{Definition of scenario}

Since methanol $\left(\mathrm{CH}_{3} \mathrm{OH}\right)$ is often discussed as an important key molecule in the context of an economy solely based on renewable energies, we chose the methanol production to illustrate our proposed method. The reasons for allocating methanol such an important role are diverse. First, methanol is an industrially important commodity and the reaction chemistry is well declared. In context of energy transition, methanol is a $\mathrm{C}_{1}$-molecule to bound hydrogen $\left(\mathrm{H}_{2}\right)$, which is produced from renewable resources. Furthermore, carbon dioxide $\left(\mathrm{CO}_{2}\right)$ can be used as carbon source. While this is also valid for methane $\left(\mathrm{CH}_{4}\right)$, methanol is a liquid at ambient condition. This is highly beneficial when considering storage and handling, in particular for mobility purposes.

The methanol molecule consists of one carbon, one oxygen and four hydrogen atoms. In principle these atoms can be provided by any other $C, O$ or $H$ containing molecule. However, methanol is industrially synthesized from synthesis gas that mainly contains of $\mathrm{CO}, \mathrm{CO}_{2}$ and $\mathrm{H}_{2}$. The conventional feedstock for the production of synthesis gas is based on fossil sources, such as coal or natural gas and steam reforming and coal gasification are the important process technologies for the conversion.

In contrast, we also considered renewable sources and corresponding technologies in order to account for a sustainable production system. Promising technologies are the anaerobic digestion and the subsequent reforming step, usage of electrical energy for the electrochemical splitting of water into hydrogen and using carbon dioxide as carbon source. Therefore, the RWGS or carbon dioxide electrolysis come also into the focus of interest. Tab. S2 lists all conversion processes which are considered in this analysis.

Two main indicators, the specific cost $c_{s}$ in $€ / t_{\mathrm{CH}_{3 \mathrm{OH}}}$ and specific carbon dioxide emission 
$e_{s}$ in $t_{\mathrm{CO}_{2}} / t_{\mathrm{CH}_{3} \mathrm{OH}}$, are introduced for the evaluation of the economic and ecologic impact of the methanol production. Both indicators are influenced by the production process (in form of equipment cost and energy demand) and by the resource used (in form of energy specific cost and energy specific emission). The feedstock sources, cost and $\mathrm{CO}_{2}$-emissions for the energy supply are given in Tab. 3. In the present study the energy conversion efficiencies were estimated to be $40 \%$ for coal power plants and $55 \%$ for CHP plants converting natural gas into electrical power.

In Tab. 3 it is visible that sources with lower specific $\mathrm{CO}_{2}$-emissions tendentially have higher specific cost. Only the use of nuclear power shows both low cost and low emissions. However, nuclear power is no future option for Germany due to the political decision of nuclear phase-out until $2022^{42}$. Also consequential cost e.g. caused by final disposal are not considered, which finally would lead to increased cost for the usage of nuclear power.

For the analysis a case scenario was defined and Tab. 4 lists the specifications and considered conditions. The cost for $\mathrm{CO}_{2}$-emissions was fixed to $5 € / \mathrm{t}_{\mathrm{CO}_{2}}$, which is the current stock exchange traded $\mathrm{CO}_{2}$ European Emission Allowances price. As a further constraint no emission of carbon monoxide (CO) is desired since its toxicity. Thus, all CO that is formed in the overall production is either consumed or oxidized into $\mathrm{CO}_{2}$. 
Table 3: Comparison of different energy sources

\begin{tabular}{|c|c|c|c|}
\hline $\begin{array}{l}\text { Energy Source } \\
\text { Unit }\end{array}$ & $\begin{array}{c}\text { Cost } \\
\mathrm{ct} / \mathrm{kWh}\end{array}$ & $\begin{array}{c}\mathrm{CO}_{2} \text {-emission } \\
\mathrm{g} / \mathrm{kWh}\end{array}$ & References \\
\hline \multicolumn{4}{|l|}{ Electrical energy } \\
\hline Lignite & 3.3 & 1025 & $43-45$ \\
\hline Bituminous coal & 2.8 & 925 & $43-45$ \\
\hline Natural gas & 4.2 & 475 & $43-45$ \\
\hline Biomass & 9.6 & $100^{*}$ & $43-45$ \\
\hline German power-mix & $5.9^{* *}$ & 535 & $43,44,46$ \\
\hline Nuclear energy & 3.5 & 10 & $43-45$ \\
\hline Water & 10.2 & 10.5 & $43-45$ \\
\hline Photovoltaic & 30 & 50 & $43-45$ \\
\hline Wind (onshore) & 10.1 & 11 & $43-45$ \\
\hline Wind (offshore) & 13.1 & 11 & $43-45$ \\
\hline \multicolumn{4}{|l|}{ Heat supply } \\
\hline Lignite & 1.3 & 410 & $43-45$ \\
\hline Bituminous coal & 1.1 & 370 & $43-45$ \\
\hline Natural gas & 2.3 & 260 & $43-45$ \\
\hline Biomass & 5.3 & $55^{*}$ & $43-45$ \\
\hline German power-mix & $6.2^{* *}$ & 565 & $43,44,46$ \\
\hline Wind (onshore) & 10.7 & 11.5 & $43-45$ \\
\hline Wind (offshore) & 13.8 & 11.5 & $43-45$ \\
\hline
\end{tabular}

Table 4: Definition of scenario

\begin{tabular}{|c|c|c|c|}
\hline Parameter & Symbol & Unit & Value \\
\hline \multicolumn{4}{|l|}{ Operational conditions } \\
\hline Plant capacity & $\dot{N}_{\mathrm{CH}_{3} \mathrm{OH}, \text { out }}$ & $\mathrm{t}_{\mathrm{CH}_{3} \mathrm{OH} / \mathrm{a}}$ & 100000 \\
\hline Reference temperature & $T_{0}$ & $\mathrm{~K}$ & 298.15 \\
\hline Reference pressure & $p_{0}$ & bar & 1 \\
\hline \multicolumn{4}{|l|}{ Efficiencies } \\
\hline Power generation & $\eta_{e c}$ & - & 0.35 \\
\hline Heat supply & $\eta_{h t}$ & - & 0.85 \\
\hline \multicolumn{4}{|l|}{ Economics } \\
\hline Rate of interest & $z$ & $\%$ & 6 \\
\hline Payback time & $n$ & $\mathrm{a}$ & 20 \\
\hline \multicolumn{4}{|l|}{ Heat Exchange } \\
\hline Heat exchanger area cost & $c_{H X}$ & $€ / \mathrm{m}^{2}$ & 200 \\
\hline Heat transfer coefficient & $k$ & $\mathrm{~W} / \mathrm{m}^{2} \mathrm{~K}$ & 50 \\
\hline Min. temp. difference & $\Delta T_{\min }$ & $\mathrm{K}$ & 10 \\
\hline \multicolumn{4}{|l|}{ Emissions } \\
\hline $\mathrm{CO}_{2}$-certificate price & $c_{\mathrm{CO}_{2}}$ & $€ / \mathrm{t}_{\mathrm{CO}_{2}}$ & 5 \\
\hline
\end{tabular}




\section{Results}

For the methanol production process a systematic evaluation of different feedstock sources as well as different energy sources was carried out with the proposed linear programming approach. The different possible sources for both feedstock and energy supply are given in Tab. 3. Fossil based energy sources, such as coal and natural gas as well as renewables, such as biomass, wind and photovoltaics are considered. Furthermore, for the transition period the current German power mix and nuclear power are taken into account. For the carbon feedstock fossil and renewable sources are considered, i.e. lignite and bituminous, natural gas, biomass and $\mathrm{CO}_{2}$. The $\mathrm{CO}_{2}$ source is not further specified in the following analysis but it was assumed that $\mathrm{CO}_{2}$ was purchased for the $\mathrm{CO}_{2}$-certificate price given in Tab. 4 .

The first main indicator, the specific methanol production cost, was directly obtained by solving the linear program and dividing the TAC of the optimal process configuration by the methanol product flux. In order to evaluate also the second indicator, the specific carbon dioxide emission, Eq. (32) was applied to compute the total $\mathrm{CO}_{2}$-emissions $E_{\mathrm{CO}_{2}}$ of the overall production process.

$$
E_{\mathrm{CO}_{2}}=e_{\mathrm{CO}_{2}, \dot{Q}} \cdot \sum_{j=1}^{M} \dot{Q}_{\text {ext }}^{(j)}+e_{\mathrm{CO}_{2}, \dot{W}} \cdot \sum_{j=1}^{M} \dot{W}_{e x t}^{(j)}+\dot{N}_{\mathrm{CO}_{2}, \text { out }}
$$

Eq. (32) accounts for both the direct emission $\left(\dot{N}_{\mathrm{CO}_{2}, \text { out }}\right)$ and also the indirect emissions caused by the energy supply $\left(\dot{Q}_{e x t}^{(j)}, \dot{W}_{e x t}^{(j)}\right)$ of all processes $j$.

\section{Evaluation of different feedstock and energy sources}

Initially, the dependence of the indicators, specific methanol production $\operatorname{cost} c_{s}$ and specific $\mathrm{CO}_{2}$-emissions $e_{s}$, on the different feedstock and energy sources were examined. Therefore, systematically for each combination of feedstock, heat and power source as listed in Tab. 3 the linear program was solved. The results of $c_{s}$ and $e_{s}$ depending on the sources for feedstock and energy are illustrated in Fig. 3. The nine power sources can roughly be classified in 
the three categories fossil (coal and natural gas), renewable (biomass, water, photovoltaics and wind) and in a mix category characterizing the transition period (German power mix and nuclear energy). The specific cost and specific emissions as a function of feedstock and energy supply source are illustrated in a mosaic pattern plot. The different feedstock sources, depicted at the vertical axis, and heat sources, depicted at the horizontal axis, form the frames of the mosaic. Within the frames the nine possible electricity sources are clustered in a in a $3 \times 3$ mosaic pattern, where each element corresponds to one of the nine considered power sources. The order of the different power sources in the mosaic pattern is also given in Fig. 3 d.

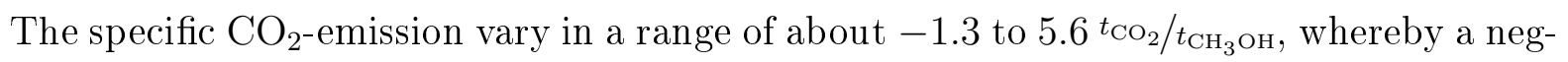
ative value means that more $\mathrm{CO}_{2}$ is consumed in the production process than emitted, which is possible if $\mathrm{CO}_{2}$ is used as feedstock. However, then the specific cost lies above $2200 € / t_{\mathrm{CH}_{3} \mathrm{OH}}$, whereas for the other considered feedstock sources only cost between 132 and $583 € / t_{\mathrm{CH}_{3} \mathrm{OH}}$ were observed, which is in good accordance to other published results ${ }^{47}$.

Neglecting first $\mathrm{CO}_{2}$ as feedstock, one can observe that for fossil feedstock the specific cost are only $25-40 \%$ of the cost for biomass as feedstock. Also it is figured out that the usage of coal - lignite or bituminous - leads to slightly higher specific cost than natural gas. Similar observations can be made for the different heat and power sources. Switching from fossil energy carriers to renewable energies leads to higher specific cost. However, a stronger influence for the heat source than for the power source on the cost were noticed. This is reasoned in the fact that for the methanol production, except for $\mathrm{CO}_{2}$ as feedstock, classical petrochemical processes are preferable which results in a higher heat than power demand. In terms of the specific $\mathrm{CO}_{2}$-emission the processes using coal either as feedstock or as energy supply source show the highest emissions, which however can be drastically decreased if renewable energy sources are exploited. However, for biomass this cannot be observed, since it leads to higher emissions than fossil natural gas. This is reasoned in the fact that during anaerobic digestion of biomass into biogas the coupled by-product $\mathrm{CO}_{2}$ is 

to mention that in other studies ${ }^{45}$ the coupled $\mathrm{CO}_{2}$-production in a biogas plant often is not negative considered since $\mathrm{CO}_{2}$ is consumed during the growth of the biomass. This assumption of carbon neutrality leads to drastically improved carbon footprints of biomass processes.

The challenges of a further usage of the produced $\mathrm{CO}_{2}$ becomes obvious when considering the results in Fig. 3 for $\mathrm{CO}_{2}$ as feedstock. Much energy is required since $\mathrm{CO}_{2}$ has to be chemically activated in order to convert it into methanol. This leads to high cost and also the specific $\mathrm{CO}_{2}$-emissions depend strongly on the energy source. It can be seen that on the one hand the lowest emissions or even a net consumption of $\mathrm{CO}_{2}$ can be achieved if renewable sources are exploited for the energy supply. However, on the other hand also the highest emissions are observed if the required energy is supplied from fossil sources. Therefore, it is important to emphasize that only the usage of renewable energy sources leads to a net consumption of $\mathrm{CO}_{2}$. This also means that the often discussed electrification of chemical processes $^{1}$ is only reasonable if sufficient renewable energy is available. In particular, the current German power mix as energy source would lead to a negative carbon footprint although $\mathrm{CO}_{2}$ is consumed as feedstock. In this case the indirect emissions caused by the energy demand are higher than the direct $\mathrm{CO}_{2}$-consumption.

Considering the results in this study it can be stated that natural gas as feedstock as well

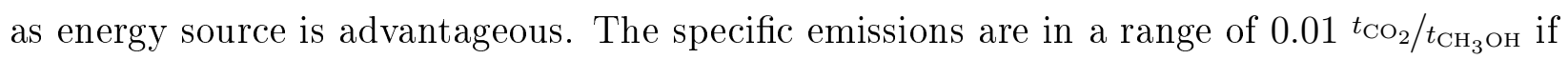

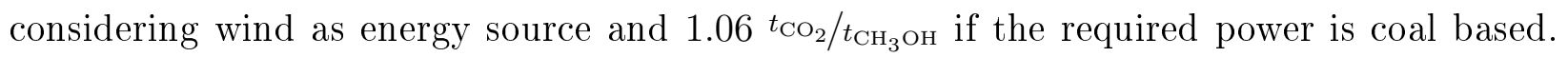
Only for the use of $\mathrm{CO}_{2}$ as feedstock lower emissions are possible. Also in terms of the specific cost natural gas performs well. The lowest obtained cost of $132 € / t_{\mathrm{CH}_{3} \mathrm{OH}}$ are achieved by using natural gas as feedstock and the highest cost for natural gas of $323 € / t_{\mathrm{CH}_{3} \mathrm{OH}}$ are even lower than the best results for biomass as feedstock.

As figured out a nearly zero carbon dioxide emission of methanol production can be reached for natural gas as feedstock source if the energy demand is provided from renewables. 
For further examinations as a reference case the configuration using natural gas as feedstock source and wind as heat and power supply was chosen. This configuration is marked with a star $(*)$ in Fig. 3 and shows specific cost of $222 € / t_{\mathrm{CH}_{3} \mathrm{OH}}$ and specific $\mathrm{CO}_{2}$-emissions of $0.01 t_{\mathrm{CO}_{2} / t_{\mathrm{CH}_{3} \mathrm{OH}}}$. In Fig. $3 \mathrm{c}$ we analyzed the theoretical prices of $\mathrm{CO}_{2}$-certificates which are required in order to make the reference configuration cost optimal. A resulting certificate price of zero means either the corresponding configuration shows a lower emission than the reference configuration (e.g. for some $\mathrm{CO}_{2}$-processes with a net $\mathrm{CO}_{2}$ consumption) or the configuration cannot become cost optimal independent on the certificate price. This is the case for biomass feeded configurations which are more expensive although the specific emissions are higher than at the reference case.

It becomes obvious that the current certificate price of about $5 € / \mathrm{t}_{\mathrm{CO}_{2}}$ is not sufficient for the support of renewable energies. Our analysis gives prices in the range of about $50-$ $150 € / \mathrm{t}_{\mathrm{CO}_{2}}$ in order to achieve competitive specific production cost for a fossil and renewable based production. This is in agreement with other studies that also estimate the need of prices for $\mathrm{CO}_{2}$-certificate in the range of $50-110 € / \mathrm{t}_{\mathrm{CO}_{2}}$ until 2050 in order to achieve the climate goals $^{48}$.

Not only the information about cost and emissions obtained in the analyses before but also the structure of the production network is crucial. Structure information are directly delivered by the proposed method since all mass and energetic fluxes are decision variables of the LP. In this way, the optimal flux distribution of all internal and external fluxes is determined. In Fig. 3 each element of the mosaic pattern corresponds to one process configuration. These configurations differ in the sources for feedstock and energy supply or also in the overall process structure and involved processes. In Fig. 4 for each type of feedstock source (coal, natural gas, biomass and $\mathrm{CO}_{2}$ ) the configuration with the lowest specific production cost (red background) and additionally the cost optimal configuration that simultaneously shows the lowest $\mathrm{CO}_{2}$-emission (green background) is illustrated. Since the process structures are equal for configurations using lignite or bituminous as feedstock, the 
type of coal is not distinguished in the following.

As also derived from the mosaic plots one can see that the coal and biomass feeded processes have direct $\mathrm{CO}_{2}$-emissions which is mainly the reason for the high specific emissions. Two processes appear in every process configuration, namely the methanol synthesis process for the conversion of synthesis gas into methanol and the steam generator for the supply of steam. Depending on the feedstock source at least one further process is present for the conversion of the feestock. In case of coal it is coal gasification, in case of natural gas a reforming process and for the biomass the anaerobic digestion in order to form methane. Considering $\mathrm{CO}_{2}$ as feedstock electrochemical electrolysis processes appear to provide $\mathrm{CO}$ and $\mathrm{H}_{2}$ from $\mathrm{CO}_{2}$ or $\mathrm{H}_{2} \mathrm{O}$. For the electrochemical processes the electrical grid as power supply is depicted in addition to heat utilities. However, also for the other processes electrical energy is required, e.g. for adjusting pressure levels. In these cases the power demand is rather low compared to the heat demand and thereby not depicted in Fig. 4. All obtained results are derived for the considered scenario conditions given in Tab. 4 .

In the following briefly a sensitivity analysis is carried out in order to examine the influence of the scenario conditions on the specific cost and specific $\mathrm{CO}_{2}$-emissions. In particular the influence of uncertainties in cost for electrical energy and $\mathrm{CO}_{2}$-certificates is examined. In Fig. 5 the optimal specific production cost and corresponding $\mathrm{CO}_{2}$-emissions are illustrated for different cost levels. The electricity price is depicted at the horizontal axis and the $\mathrm{CO}_{2}$-certificate prices at the vertical axis. The analysis is performed for natural gas as feedstock as well as heat supply and wind as energy supply source. As expected the specific production cost raise with increasing power and certificate cost. The influence of the electricity price on the production cost is much higher than the $\mathrm{CO}_{2}$-certificate prices. One can see that an increase in electricity cost of $5 \mathrm{ct} / \mathrm{kWh}$ has the same impact as an increase of about 50 to $100 € / t_{\mathrm{CO}_{2}}$ for the certificates. When comparing the electricity prices for fossil based power $(3-4 c t / k W h)$ with renewable based power $(>10 c t / k W h)$, again the urgent need for higher $\mathrm{CO}_{2}$-certificate prices becomes obvious. 
Considering also the influence on the specific $\mathrm{CO}_{2}$-emissions it can be stated that a raise of current $\mathrm{CO}_{2}$-certificate prices from 5 to $50 € / t_{\mathrm{CO}_{2}}$ would reduce the emissions by about $50-60 \%$ while the specific cost increases only by about $5-10 \%$.

\section{Analysis of combined feedstock sources}

So far the different feedstock sources were analyzed separately. Therefore, we examined also the influence of the different energy sources on the key indicators if all feedstock sources are available simultaneously. In Fig. 6 the specific cost as well as the specific emissions depending on the heat source (horizontal axis) and the power source (vertical axis) are illustrated.

As expected, the reciprocal dependence of cost and emissions can be observed. The specific cost are in a range of about 104 to $258 € / t_{\mathrm{CH}_{3} \mathrm{OH}}$ and thereby significantly lower compared to the single feedstock analysis. An even larger difference is discernible for the specific

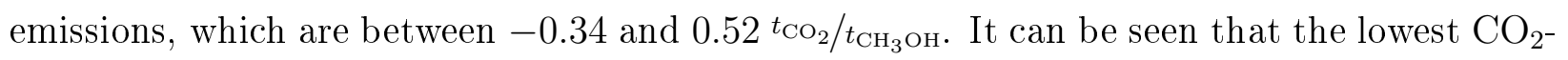
emission were achieved if renewable sources, such as wind and biomass, are used for the heat supply. However, in these cases the specific cost are high. Also using the current German power mix as heat source by electrical heating leads to low emissions if simultaneously a power source with low emissions is used, which is unexpected when considering Tab. 3. In order to examine the reason an analysis of the optimal reforming processes for the conversion of methane into synthesis gas was carried out. In Fig. 7 the optimal reforming processes for each combination of heat and power source are illustrated. One can see that three different combinations of reforming processes are obtained ((a) a combination of high temperature steam reforming (SR(HT) and dry reforming (DR), (b) dry reforming, (c) low temperature steam reforming). Except for using electricity from photovoltaic the power source does not influence the choice of the reforming process. Generally, configuration (a) becomes optimal for fossil heat supply sources while renewable sources and also the German power mix enables the low temperature steam reforming process. The corresponding process structures are illustrated in Fig. 8. For all combinations of heat and power sources a simultaneous 

the classical high temperature steam reforming is used to convert methane into synthesis gas. The endothermic steam reforming process is favored at high temperatures according to Le Chatelier's principle. Consequently, the performance of the low temperature steam reforming process is worse compared to the classical process which results in a higher power demand for the additional separation. However, more available internal heat, provided from the methanol synthesis, can be transferred internally since the heat is required at a lower temperature level for the low temperature process $\left(450{ }^{\circ} \mathrm{C}\right)$ compared to the high temperature process $\left(>900^{\circ} \mathrm{C}\right)$. Therefore, for the heat supply based on renewable resources the low temperature steam reforming process is preferred since the increase in cost for the raised power demand is lower than the reduction of external heat supply cost. Only for process configurations using power from photovoltaic a shift towards a more electrified process does not become optimal due to the high price of electricity from photovoltaics as shown in Tab. 3.

Analyzing the three different possible process configurations as shown in Fig. 8 one can see that $25 \%$ of the carbon atoms in the final methanol molecule are provided by $\mathrm{CO}_{2}$. The chemical activation of $\mathrm{CO}_{2}$ in order to convert it into other products requires much energy. Therefore, a second energy rich reactant is needed to provide a part of the energy. The second reactant is either methane that is together with $\mathrm{CO}_{2}$ converted into synthesis gas in a dry reforming process or together with hydrogen in the reverse water gas shift process. The low temperature steam reforming process (Fig. $7 \mathrm{c}$ ) becomes only optimal if the heat supply cost are significantly higher than the cost for electricity. It can be seen that in case of a renewable based heat supply, resulting in high heat supply cost, no cooling duty is required since all available heat from the methanol process is transferred internally. In case of a fossil based heat supply the available heat from methanol synthesis process is partly released to the environment because the heat exchanger cost at low temperatures becomes more expensive than external heat supply. The considered heat exchanger specifications and cost are given in Tab. 4. 
Considering the results obtained for methane as single feedstock source (Fig. 4) it becomes obvious why the combined usage of methane and $\mathrm{CO}_{2}$ as feedstock source is advantageous. Hydrogen was formed in surplus resulting in an additional outlet stream and is therefore available for the conversion of synthesis gas if $\mathrm{CO}_{2}$ is present as second reactant.

While the analysis was carried out for a low price of $\mathrm{CO}_{2}$ of $5 € / t_{\mathrm{CO}_{2}}$, it can be shown that the simultaneous usage of natural gas and carbon dioxide as feedstock is optimal also for certificate prices up to $40 € / t_{\mathrm{CO}_{2}}$. Therefore, especially during the transition period from fossil resources towards a completely renewable based production the combined usage of natural gas and $\mathrm{CO}_{2}$ is a promising option.

\section{Multiobjective optimization}

In the obtained results the strong reciprocal relation between cost and emissions could be observed. In most cases the methanol specific production cost increase with decreasing specific carbon dioxide emissions or vise versa. Therefore, a tradeoff between cost and emissions is required which is desired to be minimized. Mathematically spoken this leads to a multiobjective optimization problem. By introducing the weight factor $w \in[0,1]$ that weights the two reciprocal objectives a multiobjective function can be formulated.

$$
f(\mathbf{x})=w \cdot \mathrm{TAC}+(1-w) \cdot c_{\mathrm{CO}_{2}} E_{\mathrm{CO}_{2}}
$$

Considering the already presented results one can see that natural gas as feedstock source already gives a promising tradeoff between cost and emission. Therefore, for natural gas as feedstock the linear program applying the multiobjective function (33) was solved for each combination of heat and power source and weighting factors between 0 and 1 . The resulting Pareto optimal curve of the multiobjective optimization problem is shown in Fig. 9.

The specific $\mathrm{CO}_{2}$-emission is depicted at the horizontal axis and the specific cost at the vertical axix. Each blue dot in Fig. 9 corresponds to one optimal process configuration 
obtained by solving the multiobjective linear program. The black dashed curve is achieved by curve fitting and denotes the Pareto optimal curve. Each point along the Pareto curve depict the optimal tradeoff of both objectives. Although the datapoints are distributed, the clear trend of increasing specific cost for decreasing specific emission is recognizable. In particular for very low emissions smaller than $0.05 t_{\mathrm{CO}_{2} / t_{\mathrm{CH}_{3} \mathrm{OH}}}$ the cost increase drastically. However, in the range between 0.05 and $1 t_{\mathrm{CO}_{2}} / t_{\mathrm{CH}_{3} \mathrm{OH}}$ the slope of the curve is quite flat. This means that in case of using natural gas as feedstock a high reduction potential of $\mathrm{CO}_{2^{-}}$ emission exists at comparably small increase in cost. Such an increase of cost could easily be compensated by a political decision to raise the price of CO2-certificates. 


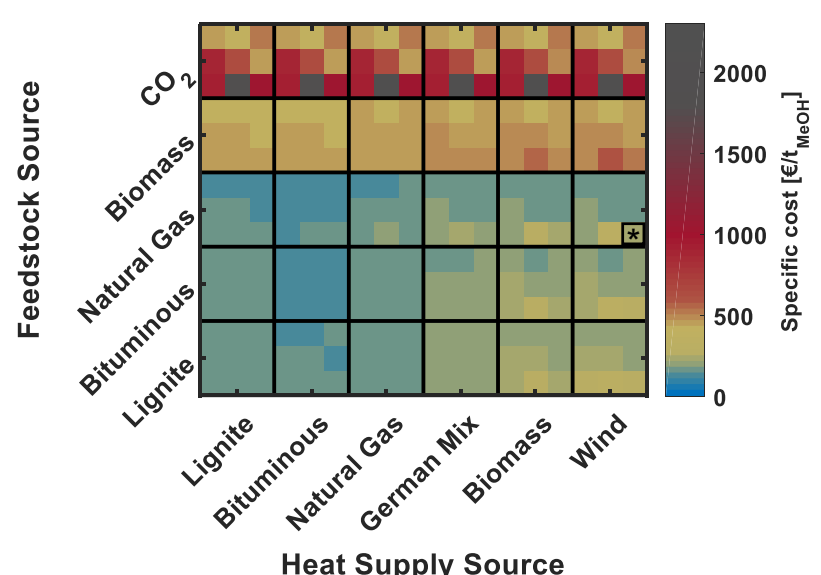

(a)

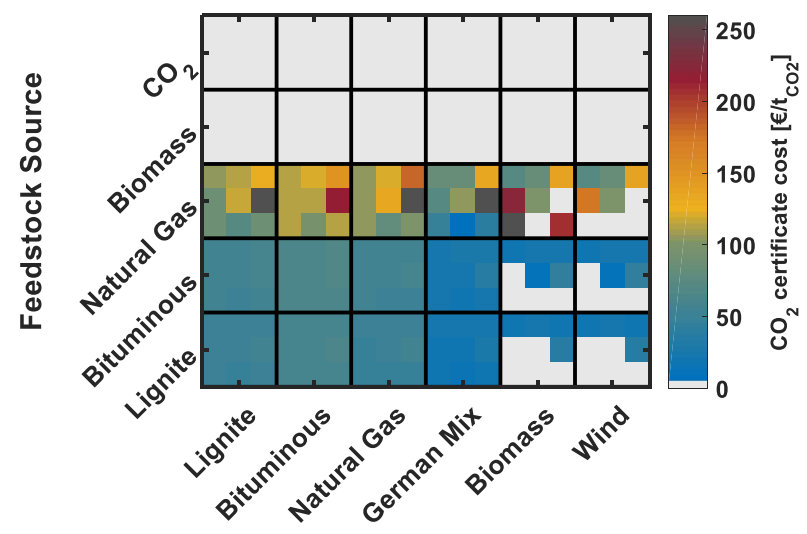

Heat Supply Source

(c)

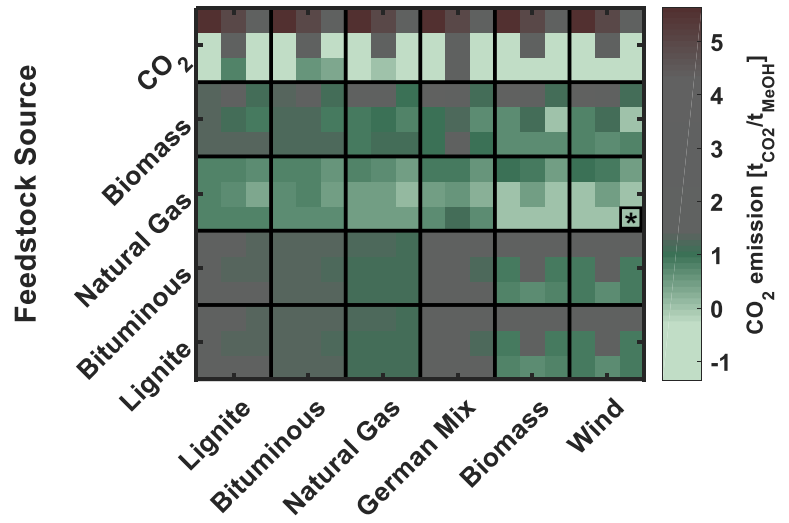

Heat Supply Source

(b)

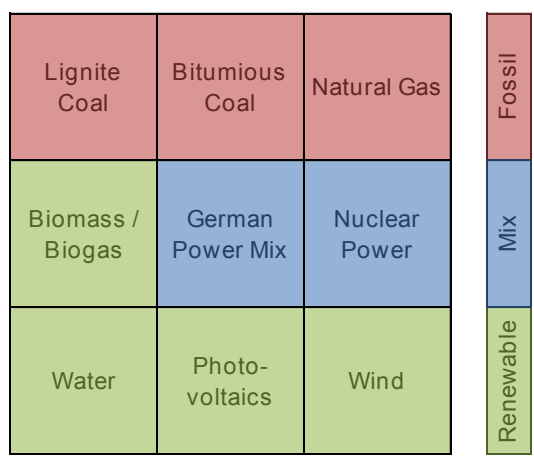

Electricity Source

(d)

Figure 3: Systematically evaluation of the influence of different sources for feedstock, heat and power supply on the specific production cost (a) and on the specific $\mathrm{CO}_{2}$-emissions (b); evaluation of required $\mathrm{CO}_{2}$-certificate cost to support low emission processes (c); order of clustered power sources $(d)$; element of reference configuration for further analysis marked with * 


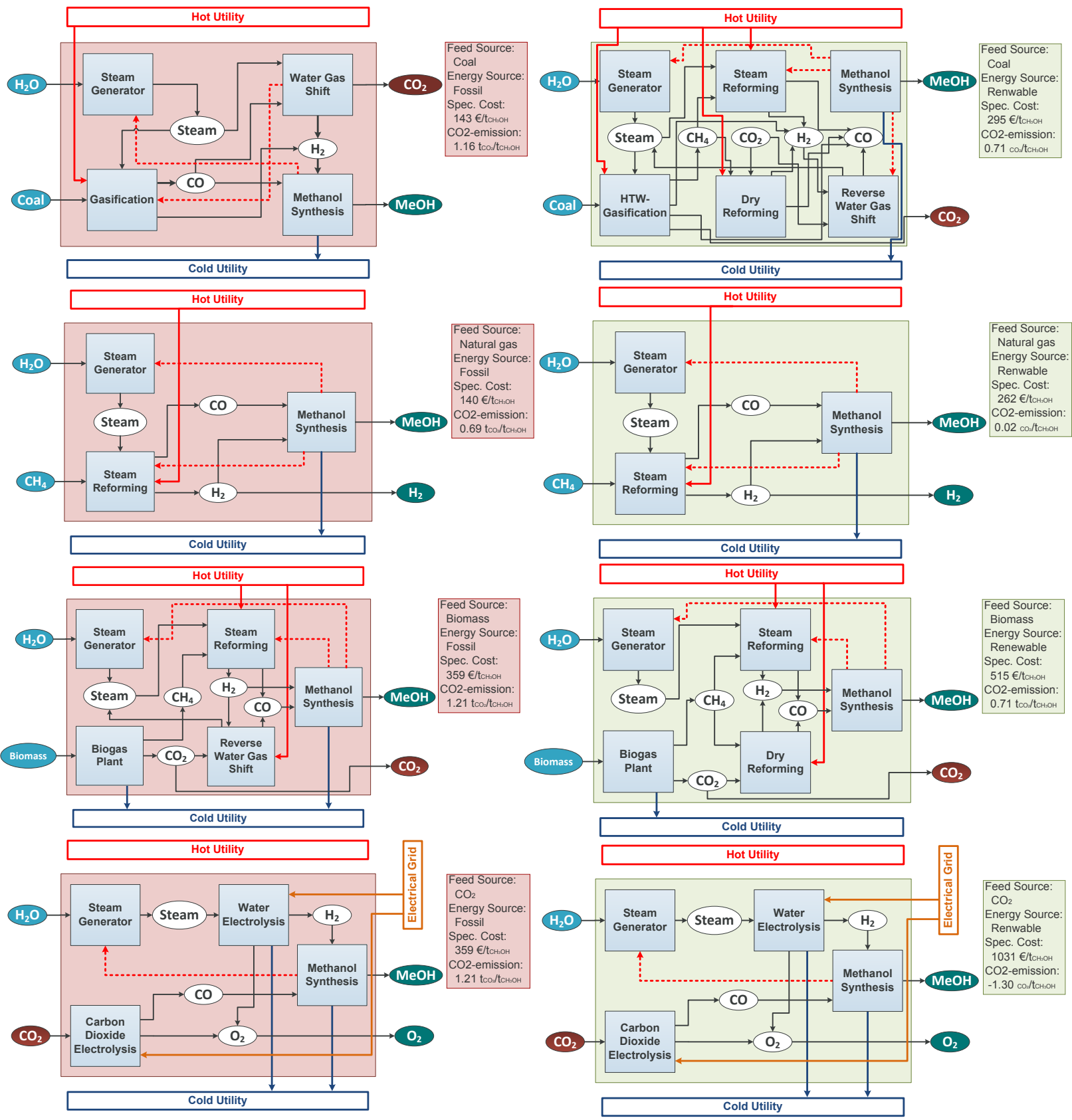

Figure 4: Schematic illustration of optimal process configurations for the different feedstock sources coal (1st row), natural gas (2nd row), biomass (3rd row) and $\mathrm{CO}_{2}$ (4th row); depicted are the overall cost optimal configurations with red background (left column) and the renewable energy provided configurations with lowest specific $\mathrm{CO}_{2}$-emission with green background (right column) 

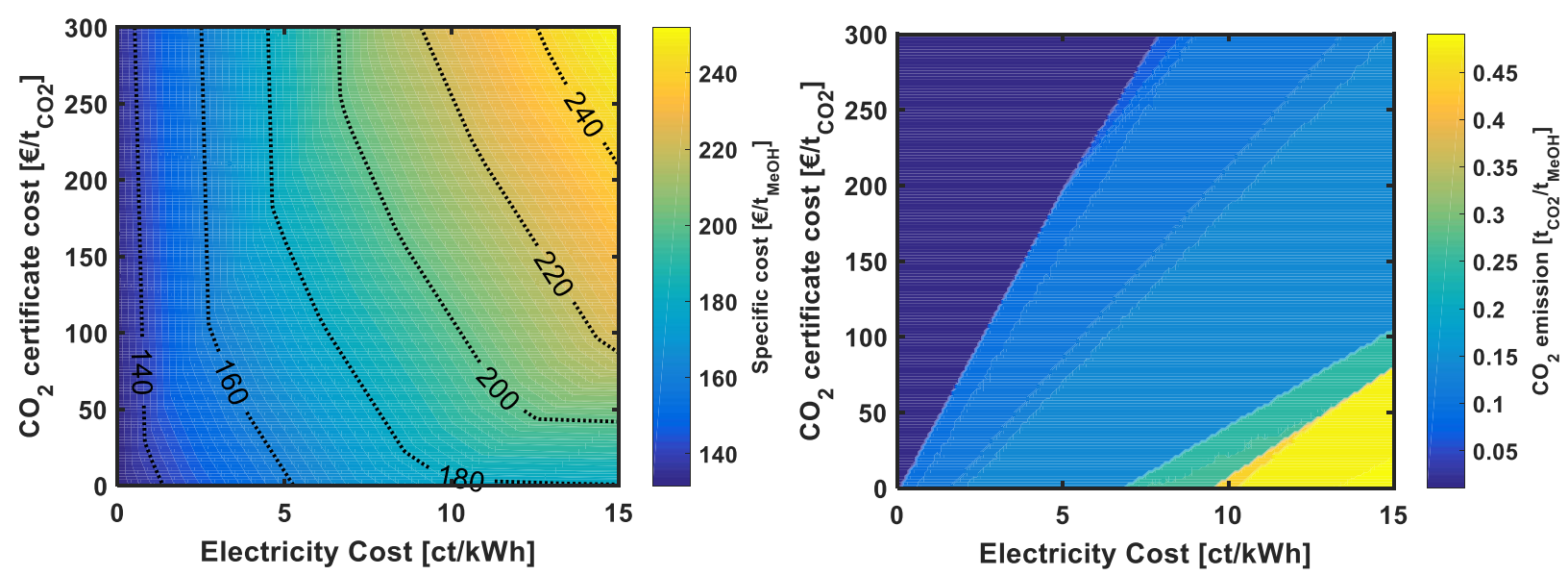

Figure 5: Influence of cost for electricity and cost for $\mathrm{CO}_{2}$-certificates on the specific production cost (left) and on the specific $\mathrm{CO}_{2}$-emissions

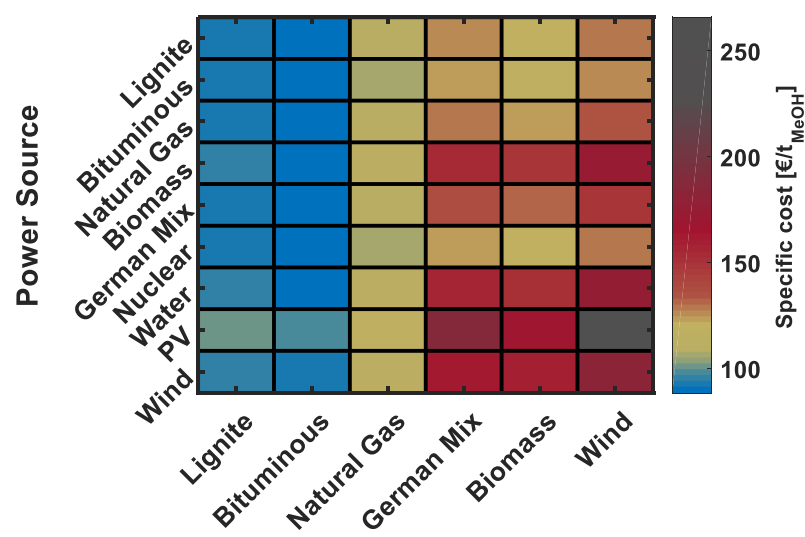

Heat Supply Source

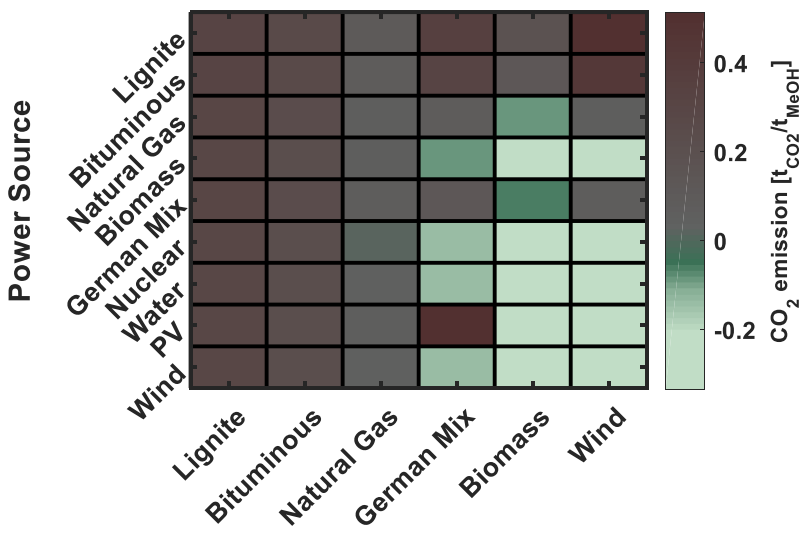

Heat Supply Source

Figure 6: Evaluation of the influence of energy supply sources on the specific cost (left) and on the $\mathrm{CO}_{2}$-emissions (right)

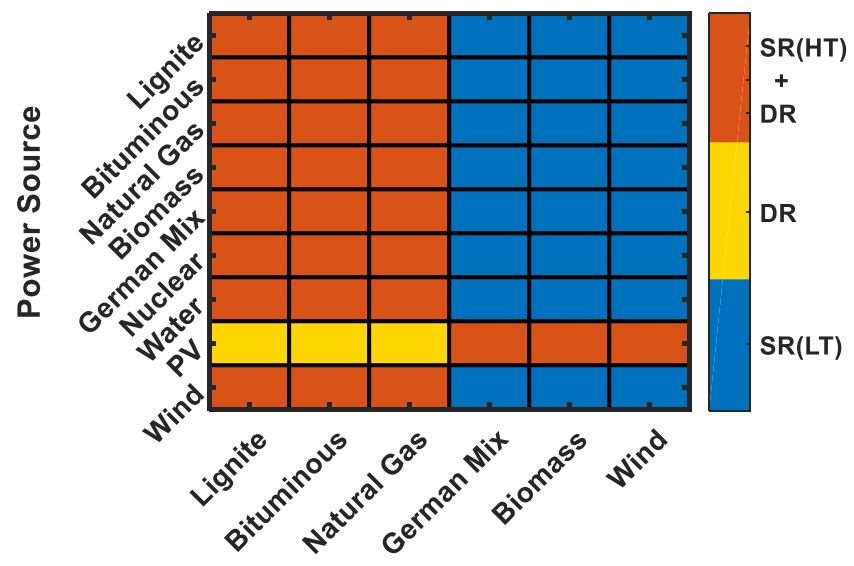

Heat Supply Source

Figure 7: Analysis of the reforming processes for the conversion of methane into synthesis gas for each combination of heat and power source 


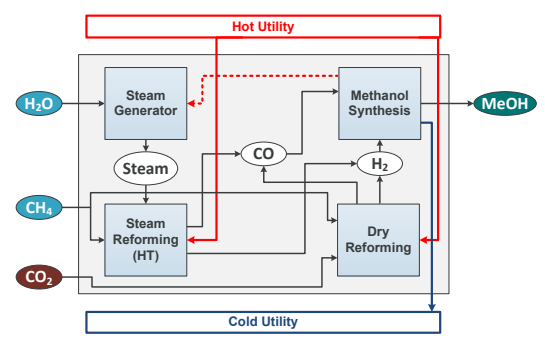

(a)

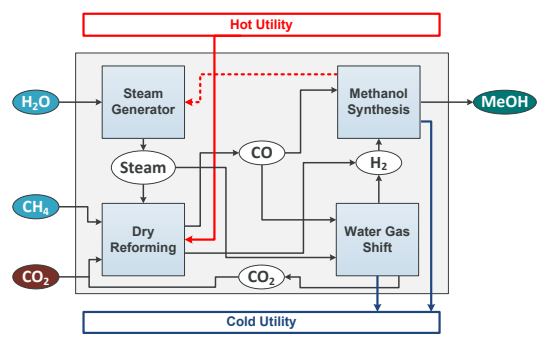

(b)

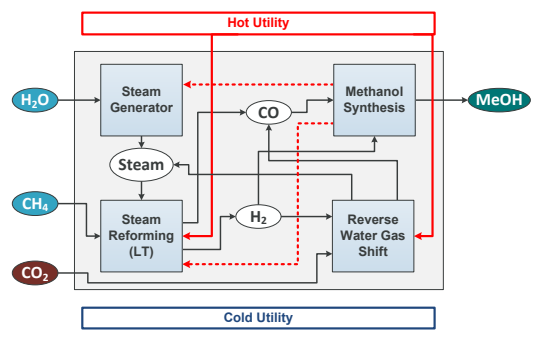

(c)

Figure 8: Flowsheets of the optimal process configuration for the methanol synthesis using methane and carbon dioxide as feedstock sources depending on different reforming processes; (a) combination of high temperature steam reforming and dry reforming; (b) dry reforming and water gas shift; (c) low temperature steam reforming and reverse water gas shift

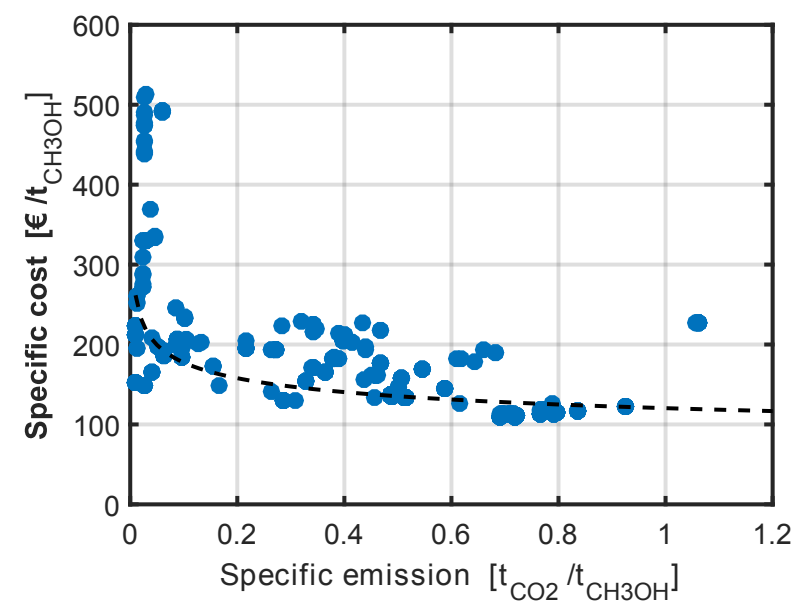

Figure 9: Pareto optimal curve of multiobjective optimization problem using natural gas as feedstock source and each combination of heat and power source for methanol synthesis 


\section{Conclusions}

In this study a linear programming approach is proposed for the structure optimization and economic evaluation of Renewables-to-Chemicals (R2Chem) production networks. The overall chemical production plant is divided into single conversion processes modeled by means of mass, enthalpy and entropy balances. Under suitable assumptions linear equations and inequalities can be derived which represent the constraints of a linear programming problem (LP). All mass and energetic fluxes within the production system appear as decision variables in the LP. Furthermore, by introducing an extent variable for each process, $\dot{\xi}$, it is possible to establish a model formulation without binary decision variables. By use of the extent variable binary decisions are relaxed such that the optimizer is able to take the decision whether the corresponding process in the superstructure should be active or not. In order to compare the different alternatives in the superstructure an economic objective function was applied. The economic model takes into account both the operating and the capital cost. Also cost for direct and indirect $\mathrm{CO}_{2}$-emissions, which are caused by the energy supply, are considered. The proposed method was applied to the methanol production process. Different feedstock as well as energy sources were systematically evaluated in terms of specific production cost and specific $\mathrm{CO}_{2}$-emissions. As a result it could be shown that natural gas gives a good tradeoff between cost and emissions. Thus, in particular for the transition period towards an economy solely based on renewables, the increased usage of natural gas for chemical production seems to be the most viable option. Moreover, it could be shown for the methanol synthesis that the lowest emissions, and even a net $\mathrm{CO}_{2}$ consumption, could be achieved if $\mathrm{CO}_{2}$ was used as feedstock thereby completely exploiting renewables for energy supply. However, the resulting production cost increase drastically since much energy for the activation of $\mathrm{CO}_{2}$ is required. One promising possibility to use $\mathrm{CO}_{2}$ as feedstock is the combination with natural gas as feedstock, provided that the $\mathrm{CO}_{2}$ is available at convenient cost. As a result of this study one also can see that the electrification of chemical processes is not economically competitive nowadays. Furthermore, a positive ecological impact is only 
realizable if renewable energies are used.

The proposed process network design methodology is a simple, yet very effective approach for the structure optimization of complex chemical production networks and the systematical screening and evaluation of different production pathway alternatives. Since mass and energy fluxes are optimized simultaneously also synergies between different processes, in particular internal heat transfer possibilities, are considered. One advantage of formulating a linear program is the identification of a global optimum. In this way the cost, the energy demand, $\mathrm{CO}_{2}$-emission as well as other key parameters can be estimated on a very reliable basis. Also the sensitivity of different process configuration on the overall process performance can be assessed since it is easily possible to analyze a given process at different temperature and pressure conditions. In this way our tool also may help answering questions regarding the impact of catalyst development for key processes on the overall process system performance. Moreover, it is conceivable to assess novel process pathways if the method is applied to less established chemical reaction systems.

However, the method has some limitations. In order to find a linear model formulation of the overall process the subprocesses are considered as black boxes. In this way only interactions between single processes can be analyzed and optimized. Questions regarding the internal design of these processes in terms of process units cannot be addressed applying the proposed method. Thus, in a future work it is required to split up the overall process box into subunits, such as reactors, separators and auxiliary units. Then, not only thermodynamic but also kinetic effects could be included in the system optimization and thereby cost could be estimated much more precisely. However, by applying the proposed approach it is possible to screen a large chemical superstructure in order to find the most promising process pathways. These candidates could be examined in detail subsequently by means of more rigorous process simulation and optimization tools. 


\section{Supporting Information Available}

- Supporting_Information.pdf: Figure S1: influence of energy conversion efficiency on energetic fluxes; Figure S2: driving force for internal heat transfer; Figure S3: linearized dependency of investment cost on the energy loss; Table S1: thermodynamic data; Table S2: considered conversion processes

This information is available free of charge via the Internet at http://pubs.acs.org/.

\section{References}

(1) Ausfelder, F. et al. Elektrifizierung chemischer Prozesse. 2015, DECHEMA Diskussionspapier.

(2) Sternberg, A.; Bardow, A. Power-to-What? - Environmental assessment of energy storage systems. Energy $\&$ Environmental Science 2015, 8, 389-400.

(3) Götz, M.; Lefebvre, J.; Mörs, F.; McDaniel Koch, A.; Graf, F.; Bajohr, S.; Reimert, R.; Kolb, T. Renewable Power-to-Gas: A technological and economic review. Renewable Energy 2016, 85, 1371-1390.

(4) Bensmann, B.; Hanke-Rauschenbach, R.; Pena Arias, I. K.; Sundmacher, K. Energetic evaluation of high pressure PEM electrolyzer systems for intermediate storage of renewable energies. Electrochimica Acta 2013, 110, 570-580.

(5) Carmo, M.; Fritz, D. L.; Mergel, J.; Stolten, D. A comprehensive review on PEM water electrolysis. International Journal of Hydrogen Energy 2013, 38, 4901-4934.

(6) Menon, V.; Fu, Q.; Janardhanan, V. M.; Deutschmann, O. A model-based understanding of solid-oxide electrolysis cells (SOECs) for syngas production by $\mathrm{H} 2 \mathrm{O} / \mathrm{CO} 2$ co-electrolysis. Journal of Power Sources 2015, 274, 768-781. 
(7) Bornhöft, A.; Hanke-Rauschenbach, R.; Sundmacher, K. Steady-state analysis of the Anaerobic Digestion Model No.1 (ADM1). Nonlinear Dynamics 2013, 73, 535-549.

(8) Koch, K.; Lübken, M.; Gehring, T.; Wichern, M.; Horn, H. Biogas from grass silage - Measurements and modeling with ADM1. Bioresource Technology 2010, 101, 81588165.

(9) Ravaghi-Ardebili, Z.; Manenti, F.; Corbetta, M.; Pirola, C.; Ranzi, E. Biomass gasification using low-temperature solar-driven steam supply. Renewable Energy 2015, 74, $671-680$.

(10) Goeppert, A.; Czaun, M.; Surya Prakash, G. K.; Olah, G. A. Air as the renewable carbon source of the future: an overview of CO2 capture from the atmosphere. Energy \& Environmental Science 2012, 5, 7833.

(11) Otto, A.; Grube, T.; Schiebahn, S.; Stolten, D. Closing the loop: captured CO2 as a feedstock in the chemical industry. Energy \& Environmental Science 2015, 8, 32833297.

(12) von der Assen, N.; Muller, L. J.; Steingrube, A.; Voll, P.; Bardow, A. Selecting CO2 Sources for CO2 Utilization by Environmental-Merit-Order Curves. Environmental Science \& Technolology 2016, 50, 1093-1101.

(13) Lin, F.; Rothensteiner, M.; Alxneit, I.; van Bokhoven, J. A.; Wokaun, A. First demonstration of direct hydrocarbon fuel production from water and carbon dioxide by solardriven thermochemical cycles using rhodium-ceria. Energy $\&$ Environmental Science 2016, 9, 2400-2409.

(14) Choi, S.; Park, J.; Han, C.; Yoon, E. S. Optimal design of synthesis gas production process with recycled carbon dioxide utilization. Industrial \& Engineering Chemistry Research 2008, 47, 323-331. 
(15) Voll, A.; Marquardt, W. Reaction network flux analysis: Optimization-based evaluation of reaction pathways for biorenewables processing. AIChE Journal 2012, 58, 17881801.

(16) Kim, J.; Sen, S. M.; Maravelias, C. T. An optimization-based assessment framework for biomass-to-fuel conversion strategies. Energy \& Environmental Science 2013, 6, $1093-1104$.

(17) Hartono, B.; Heidebrecht, P.; Sundmacher, K. Combined Branch and Bound Method and Exergy Analysis for Energy System Design. Industrial \& Engineering Chemistry Research 2012, 51, 14428-14437.

(18) Zondervan, E.; Nawaz, M.; de Haan, A. B.; Woodley, J. M.; Gani, R. Optimal design of a multi-product biorefinery system. Computers \& Chemical Engineering 2011, 35, $1752-1766$.

(19) Floudas, C. A.; Niziolek, A. M.; Onel, O.; Matthews, L. R. Multi-scale systems engineering for energy and the environment: Challenges and opportunities. AIChE Journal 2016, 62, 602-623.

(20) Maronese, S.; Ensinas, A. V.; Mian, A.; Lazzaretto, A.; Marechal, F. Optimum Biorefinery Pathways Selection Using the Integer-Cuts Constraint Method Applied to a MILP Problem. Industrial \& Engineering Chemistry Research 2015, 54, 7038-7046.

(21) Ulonska, K.; Skiborowski, M.; Mitsos, A.; Viell, J. Early-stage evaluation of biorefinery processing pathways using process network flux analysis. AIChE Journal 2016, 62, 3096-3108.

(22) Kokossis, A. C.; Tsakalova, M.; Pyrgakis, K. Design of integrated biorefineries. Computers \& Chemical Engineering 2015, 81, 40-56. 
(23) Schack, D.; Rihko-Struckmann, L.; Sundmacher, K. Structure optimization of powerto-chemicals (P2C) networks by linear programming for the economic utilization of renewable surplus energy. Computer Aided Chemical Engineering 2016, 38, 1551-1556.

(24) Ott, J.; Gronemann, V.; Pontzen, F.; Fiedler, E.; Grossmann, G.; Kersebohm, D. B.; Weiss, G.; Witte, C. Ullmann's Encyclopedia of Industrial Chemistry; Wiley-VCH Verlag GmbH \& Co. KGaA, 2000.

(25) Luyben, W. L. Design and Control of a Methanol Reactor/Column Process. Industrial \& Engineering Chemistry Research 2010, 49, 6150-6163, 616LT Times Cited:22 Cited References Count:5.

(26) Park, N.; Park, M.-J.; Ha, K.-S.; Lee, Y.-J.; Jun, K.-W. Modeling and analysis of a methanol synthesis process using a mixed reforming reactor: Perspective on methanol production and CO2 utilization. Fuel 2014, 129, 163-172.

(27) Abrol, S.; Hilton, C. M. Modeling, simulation and advanced control of methanol production from variable synthesis gas feed. Computers $\&$ Chemical Engineering 2012, 40, 117-131.

(28) Wenzel, M.; Rihko-Struckmann, L.; Sundmacher, K. Thermodynamic analysis and optimization of RWGS processes for solar syngas production from CO2. AIChE Journal 2017, 63, 15-22.

(29) Jurkovic, D. L.; Pohar, A.; Dasireddy, V. D. B. C.; Likozar, B. Effect of Copperbased Catalyst Support on Reverse Water-Gas Shift Reaction (RWGS) Activity for CO2 Reduction. Chemical Engineering \& Technology 2017, 40, 973-980.

(30) Ye, J.; Liu, C.-j.; Mei, D.; Ge, Q. Methanol synthesis from CO2 hydrogenation over a Pd4/In2O3 model catalyst: A combined DFT and kinetic study. Journal of Catalysis 2014, 317, 44-53. 
(31) Rihko-Struckmann, L. K.; Peschel, A.; Hanke-Rauschenbach, R.; Sundmacher, K. Assessment of Methanol Synthesis Utilizing Exhaust CO2 for Chemical Storage of Electrical Energy. Industrial \& Engineering Chemistry Research 2010, 49, 11073-11078.

(32) Bang-Jensen, J.; Gutin, G. Z. Digraphs : Theory, Algorithms and Applications, 2nd ed.; Springer Monographs in Mathematics; Springer London: London, 2009.

(33) Atkins, P. W.; De Paula, J. Atkins' Physical Chemistry, 10th ed.; Oxford Univ. Press: Oxford, 2014.

(34) Linnhoff, B.; Flower, J. R. Synthesis of heat exchanger networks: I. Systematic generation of energy optimal networks. AIChE Journal 1978, 24, 633-642.

(35) Bridgwater, A. V. The functional unit approach to rapid cost estimation. AACE Bulletin 1976, 18, 153.

(36) Gaensslen, H. Thermal efficiency and production economics of chemical plants. Chemsa 1980, $6,13-15$.

(37) Peters, M. S.; Timmerhaus, K. D.; West, R. E. Plant Design and Economics for Chemical Engineers, 5th ed.; McGraw-Hill Chemical Engineering Series; McGraw-Hill Education, 2003.

(38) Lange, J. P. Fuels and chemicals manufacturing - guidelines for understanding and minimizing the production costs. Cattech 2001, 5, 82-95.

(39) Schack, D.; Rihko-Struckmann, L.; Sundmacher, K. Economic linear objective function approach for structure optimization of renewables-to-chemicals (R2Chem) networks. Computer Aided Chemical Engineering 2017, 40, 1975-1980.

(40) Reid, R. C. The Properties of Gases and Liquids; McGraw-Hill: New York, 1987.

(41) NIST, NIST Chemistry WebBook. http://webbook.nist.gov/chemistry/. 
(42) Weyland, M.; Albert, R.; Halatsch, A.; Icha, P.; Jäger, F.; Juhrich, K.; Kuhnhenn, K.; Mohr, L.; Mordziol, C.; Ollig, M.; Osiek, D.; Reinhardt, A.-S.; Schuberth, J. Stromsparen - Schlüssel für eine umweltschonende und kostengünstige Energiewende. 2015; Umweltbundesamt.

(43) Wissel, S.; Rath-Nagel, S.; Blesl, M.; Fahl, U.; A.Voß, Stromerzeugungskosten im Vergleich. 2008; Universität Stuttgart, Working Paper.

(44) Nestle, U.; Kunz, C. Studienvergleich: Stromgestehungskosten verschiedener Erzeugungstechnologien. 2014; Forschungsradar Energiewende.

(45) Wagner, H.-J.; Koch, M. K.; Burkhardt, J.; Böckmann, T. G.; Feck, N.; Kruse, P. CO2Emissionen der Stromerzeugung. BWK Das Energie-Fachmagazin 2007, 59, 44-52.

(46) Icha, P.; Kuhs, G. Entwicklung der spezifischen Kohlendioxid-Emissionen des deutschen Strommix in den Jahren 1990 bis 2015. Climate Change 2016, 26, 1-27.

(47) Bandi, A.; Specht, M. Gewinnung von Methanol aus Biomasse. 2004; Zentrum für Sonnenenergie- und Wasserstoff-Forschung Baden-Württemberg.

(48) Kunz, C. Studienvergleich: Entwicklung der Stromgroßhandels- und der CO2Zertifikatspreise. 2013; Forschungsradar Erneuerbare Energien. 


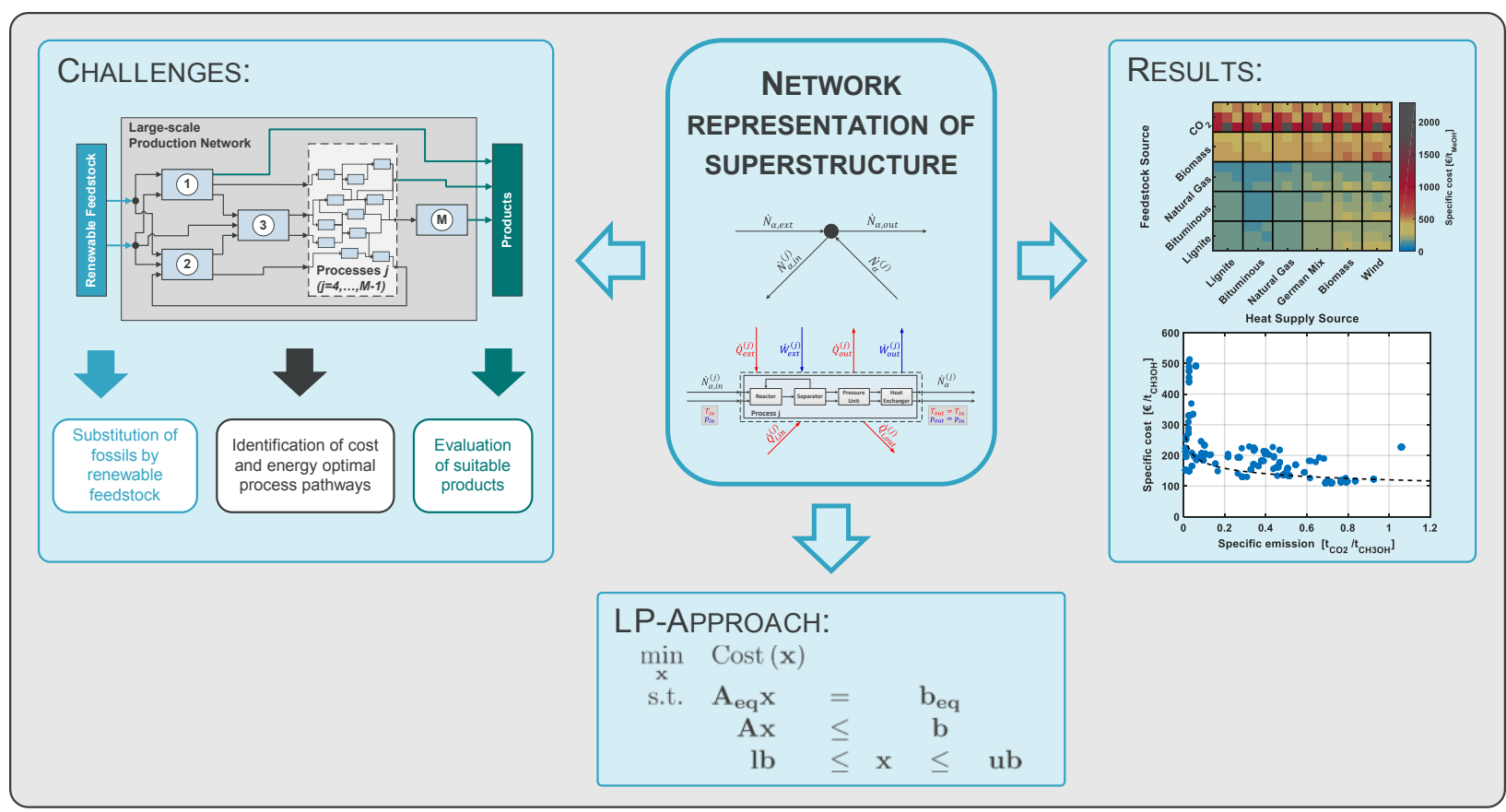

Graphical Abstract 


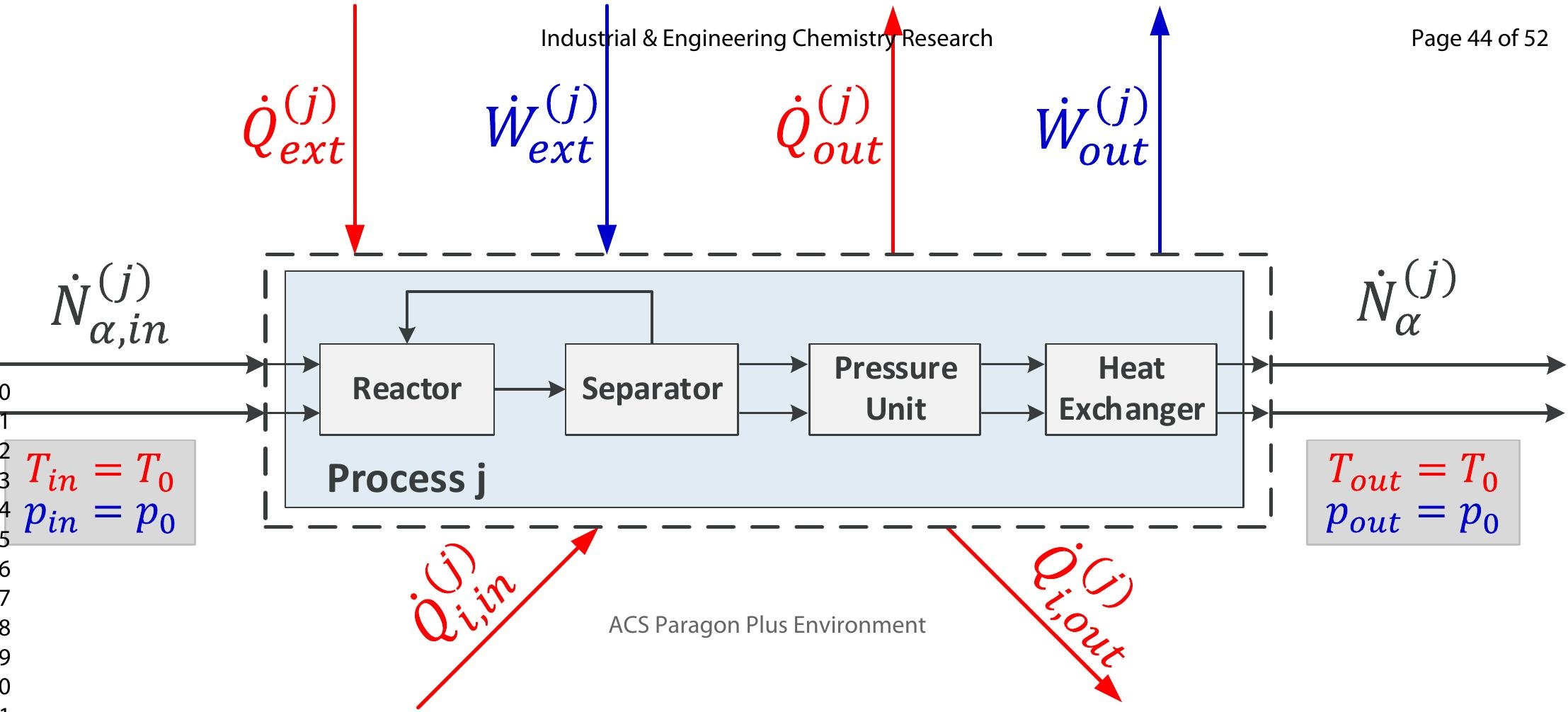




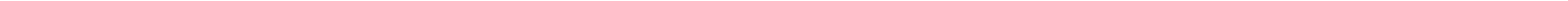



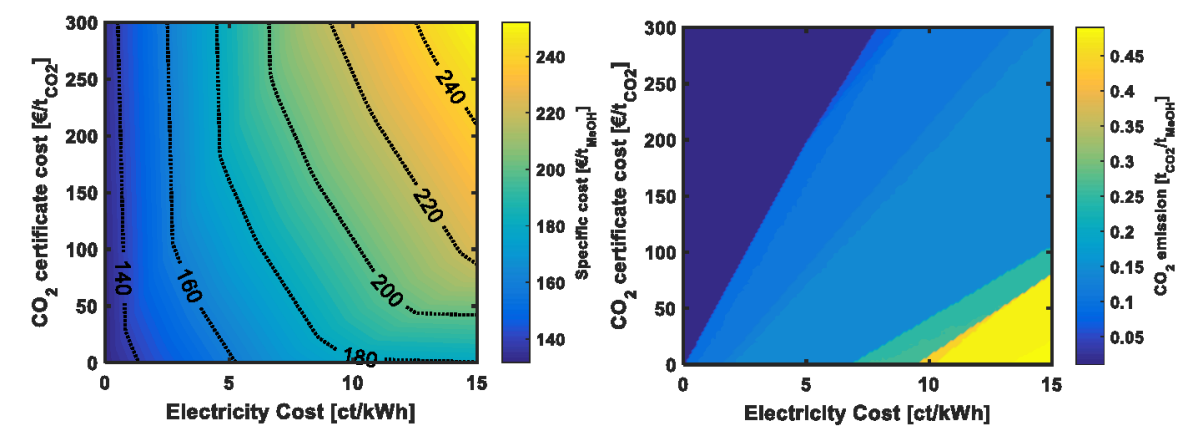


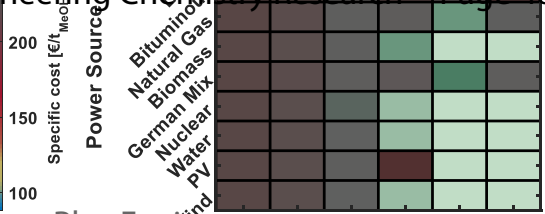

0.2

onments 


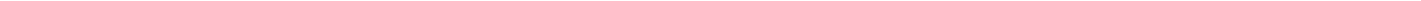


Hot Utility

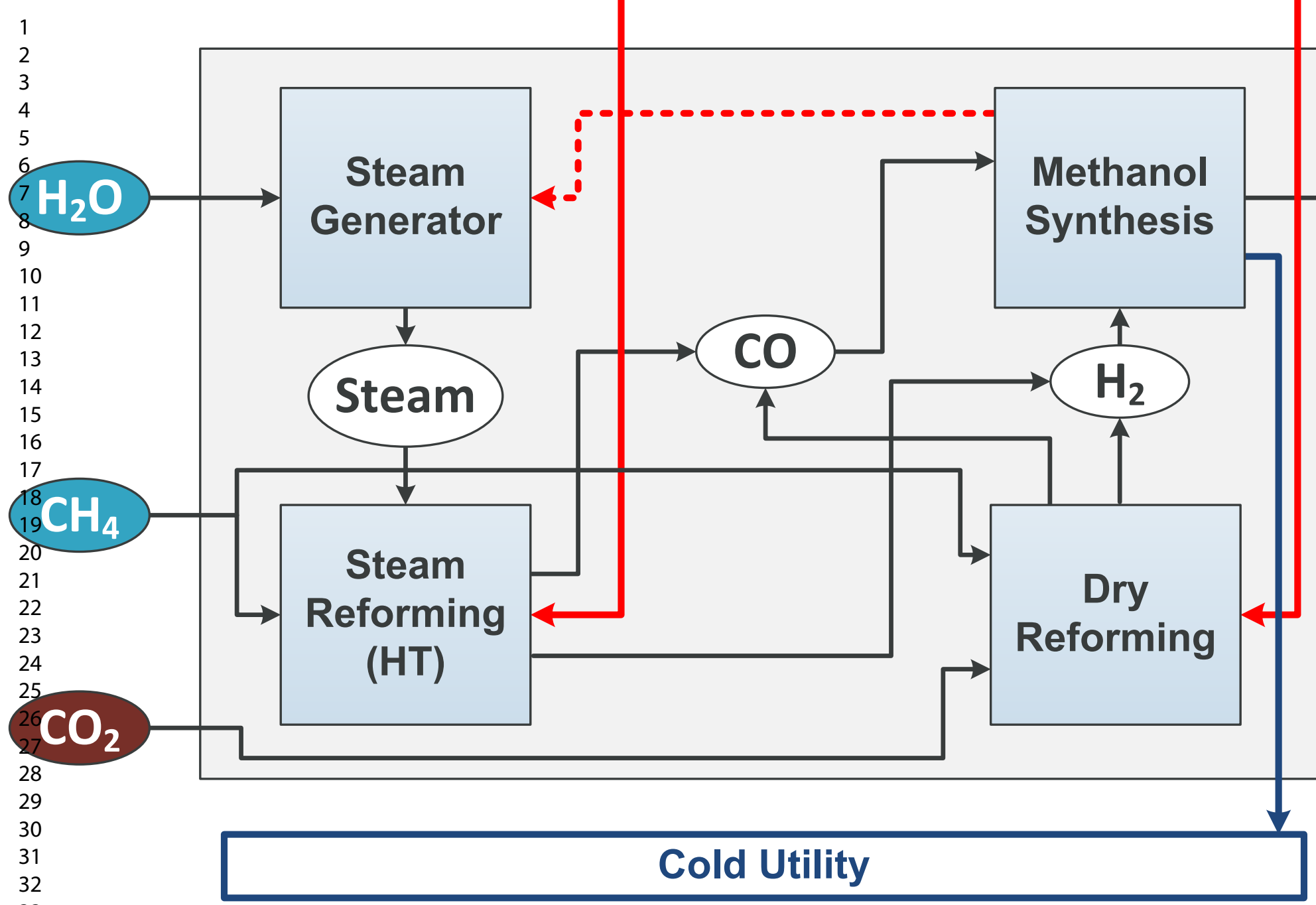

(a)

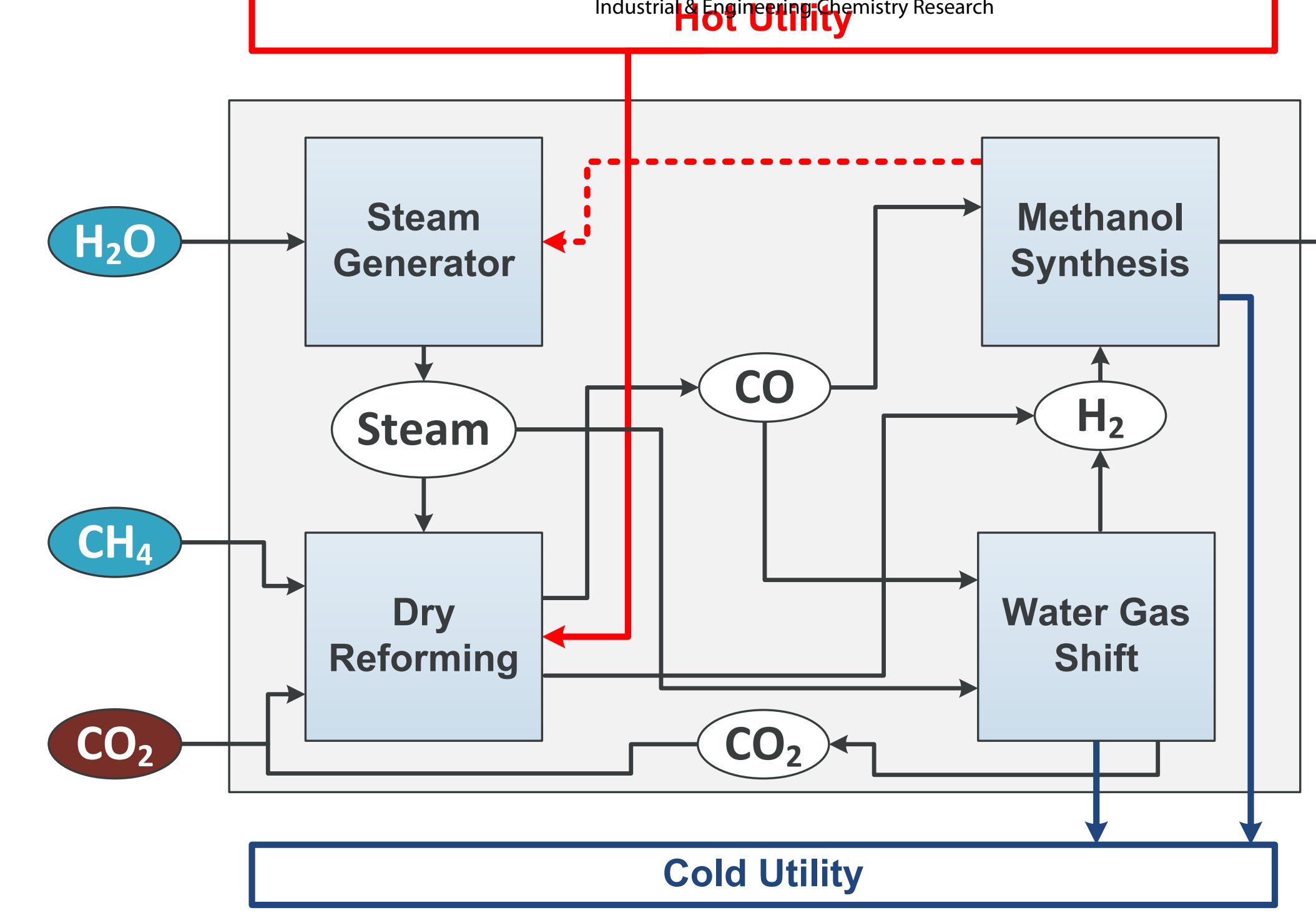

(b)
$\mathrm{MeOH}$

$\mathrm{CO}_{2}$

E)

(c) 


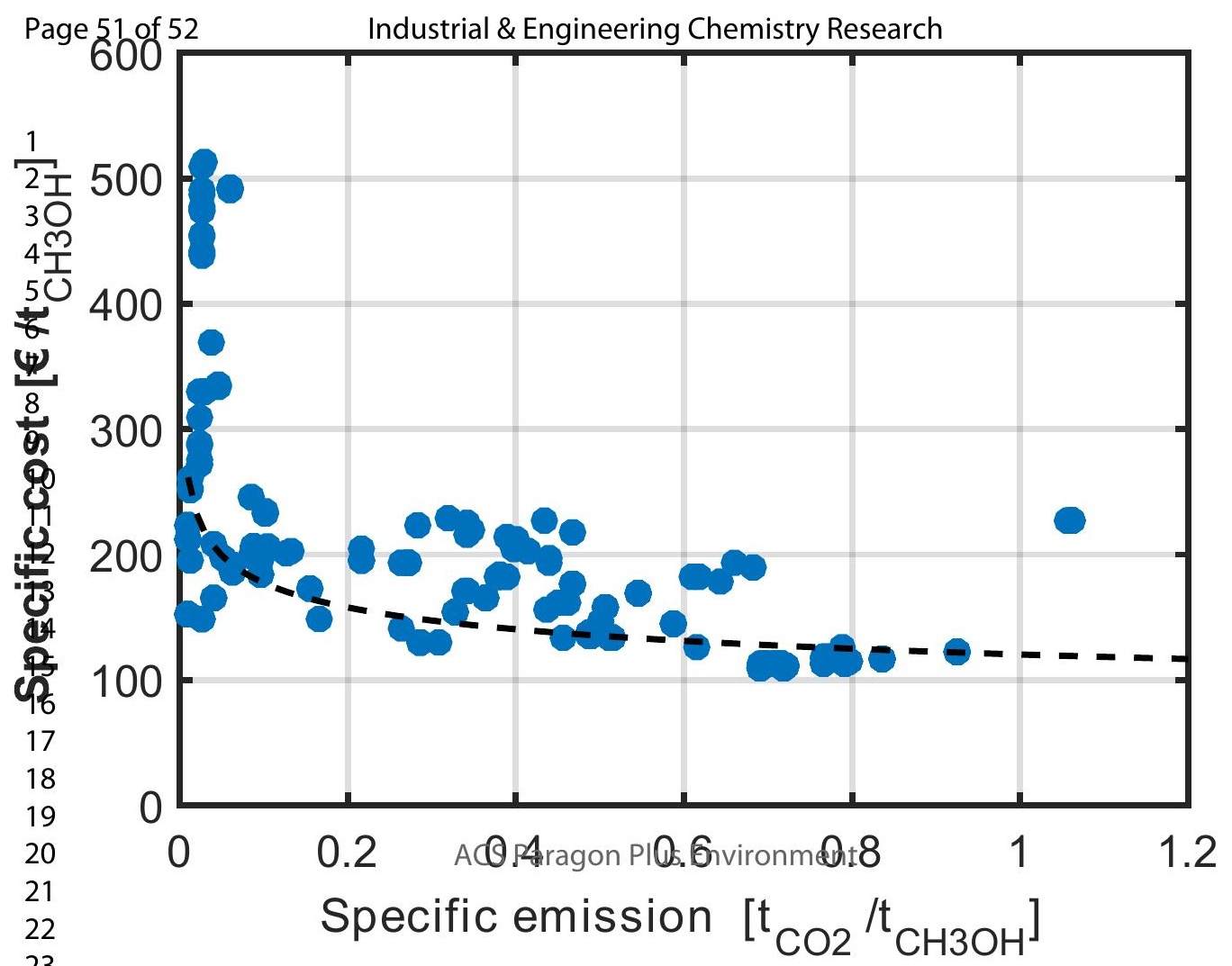




\section{CHALLENGES:}
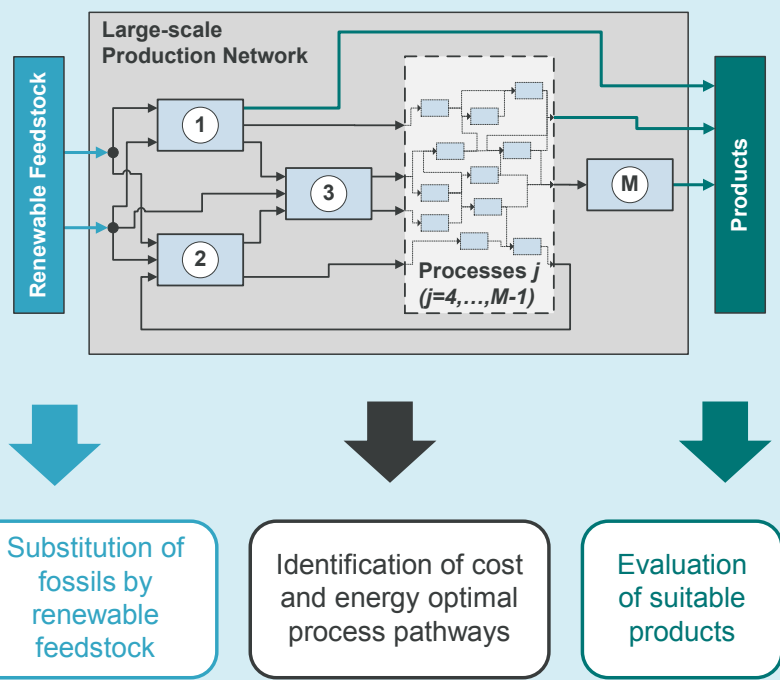

process pathways
Industrial \& Engineering Chemistry Research

\section{NETWORK \\ REPRESENTATION OF SUPERSTRUCTURE}
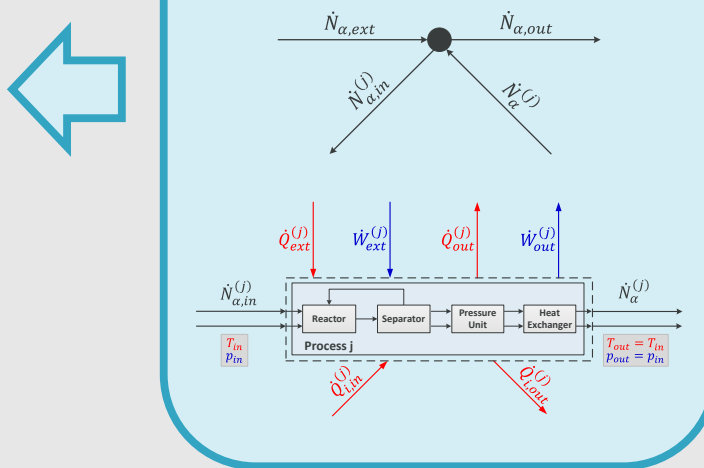

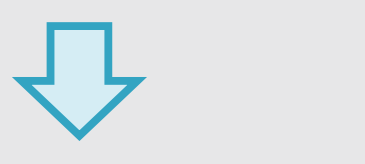

$$
\begin{aligned}
& \text { LP-APPROACH: } \\
& \min \operatorname{Cost}(\mathbf{x}) \\
& \text { s.t. } \mathbf{A}_{\mathrm{eq}} \mathbf{x}=\mathrm{b}_{\mathrm{eq}}
\end{aligned}
$$

RESULTS:

Page 52 of 52

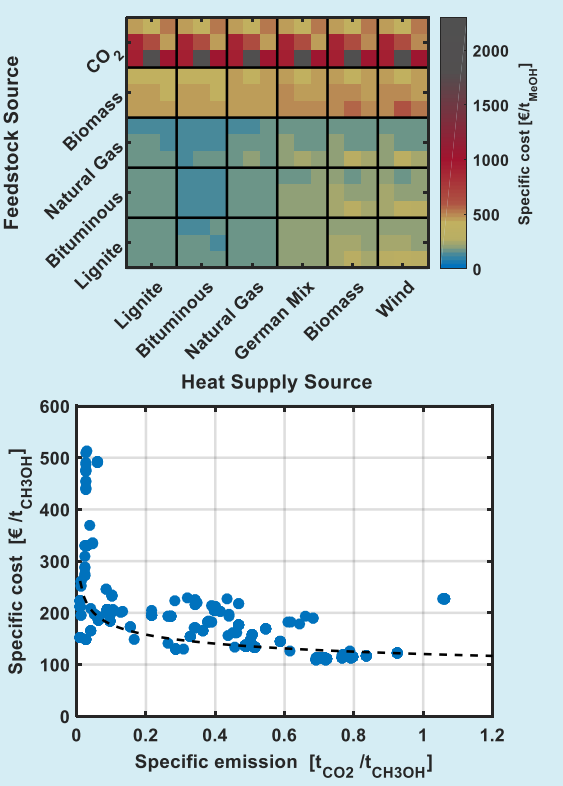

